17.

تحليل مؤشر ات الكفاعة الإقتصادية لأنماط الادارة المزرعية فى المزارع العضوية في محافظة الفيوم

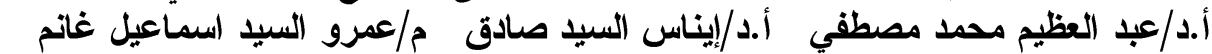
معيد

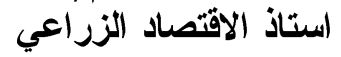
استاذ الاقتصاد الزراعي المتفرغ المعن قسم الإقتصاد الزر اعي - كلية الزر اعة - جامعة الفيوم الزئه

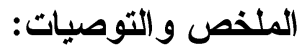

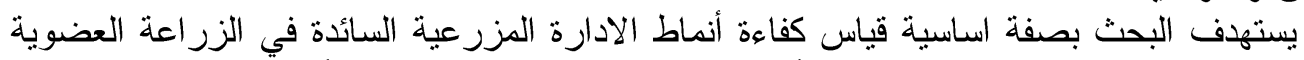

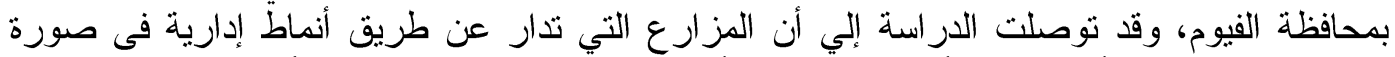

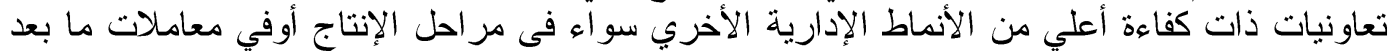

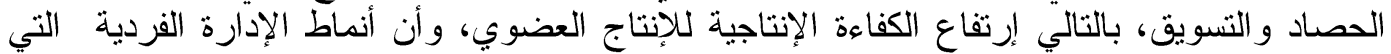

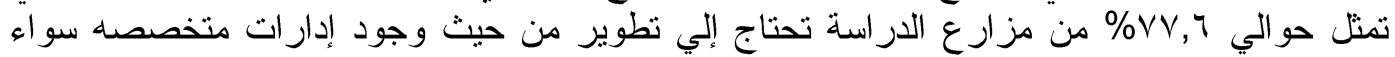

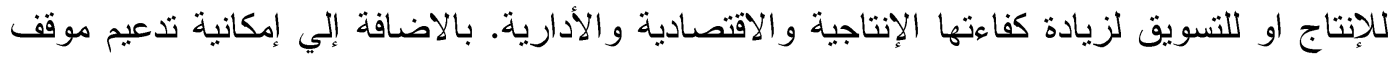

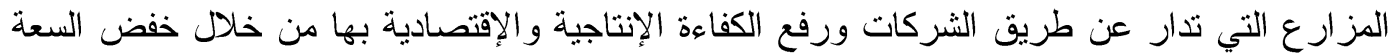

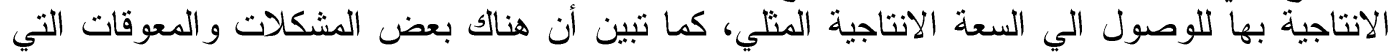

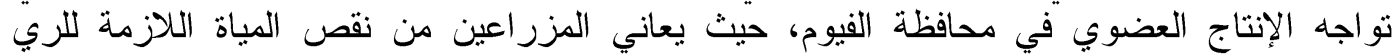

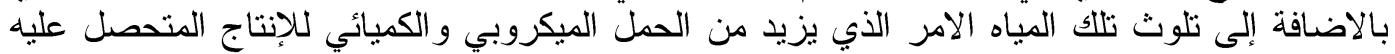

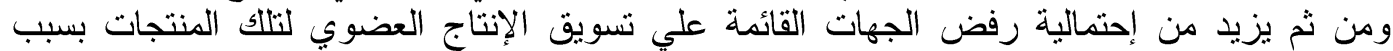

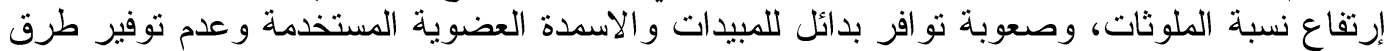

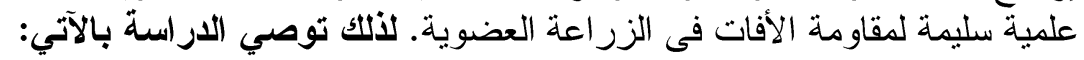

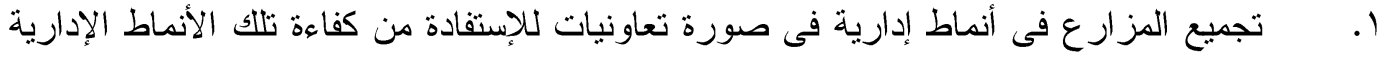

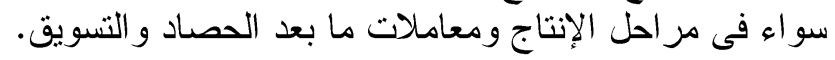

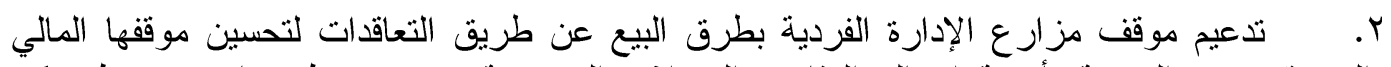

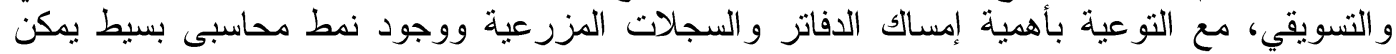
الرجوع اليه لمتابعة العمليات الإنتاجية المختلفة ومقارنة المواسم، لإتمام عمليات التقييم و المتابعة وباقي الوظائف الإدارية.

r. ضرورة إهتمام المزارع بتحليل الإنتاج العضوى المتحصل عليه من خلال سحب عينات من

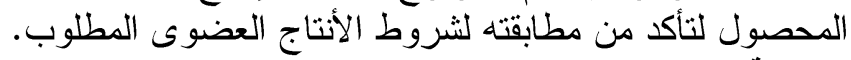

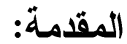

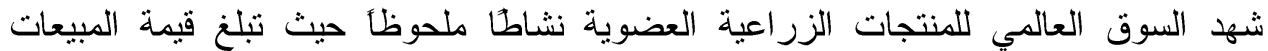

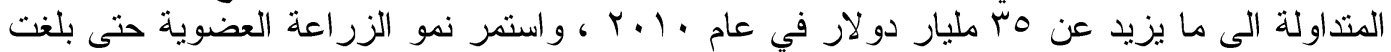

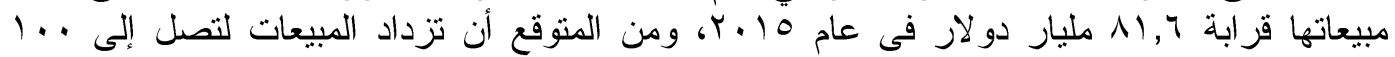

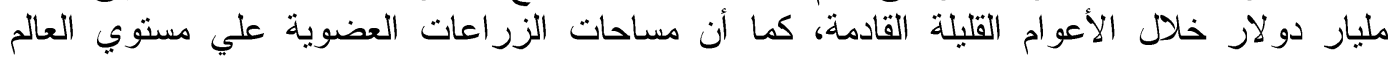

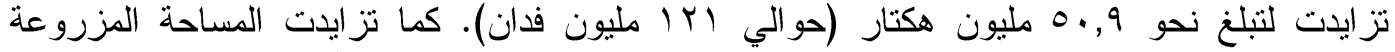

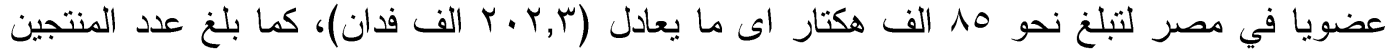

Fayoum J. Agric. Res. \& Dev., Vol. 33, No.2, July, 2019 
171

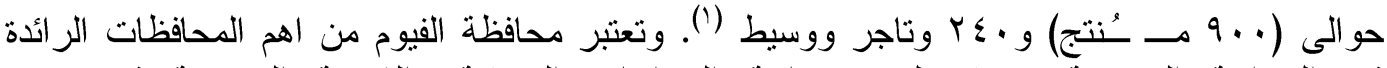

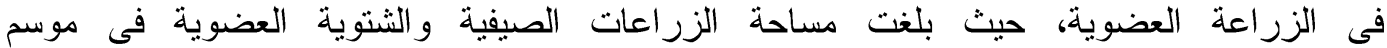

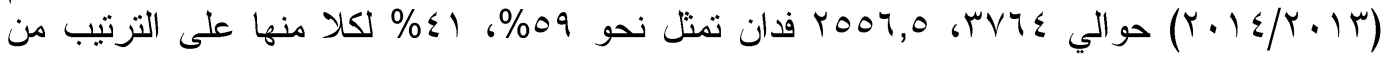

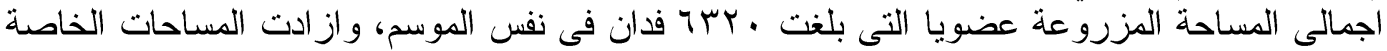

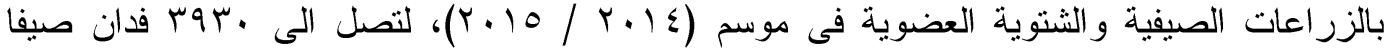

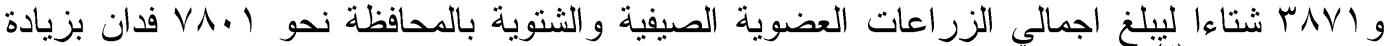

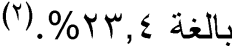

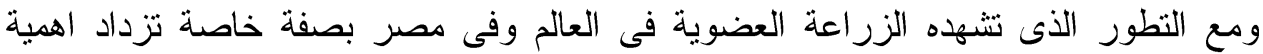

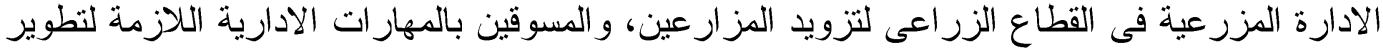

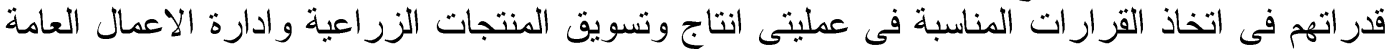

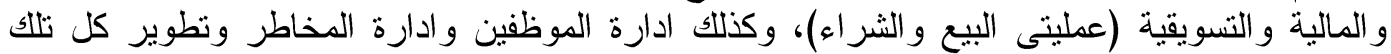

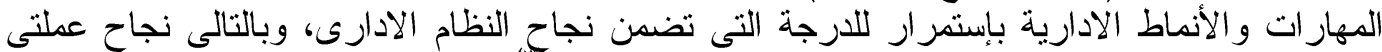

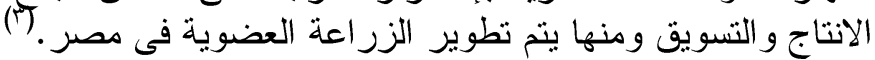

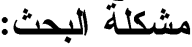

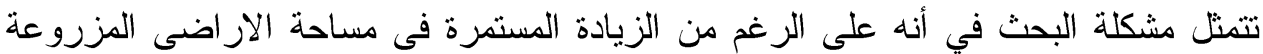

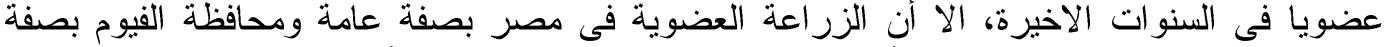

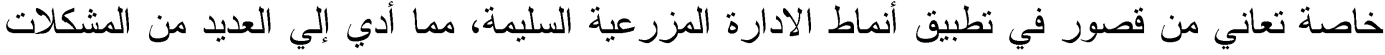

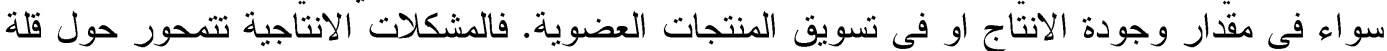

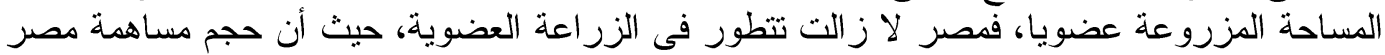

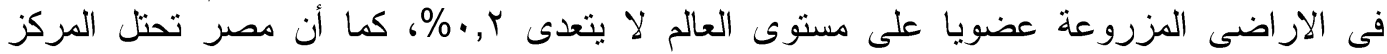

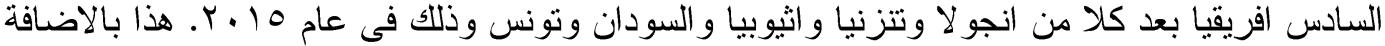

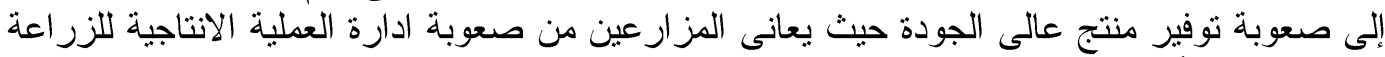

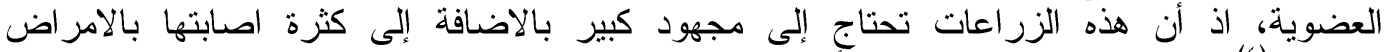

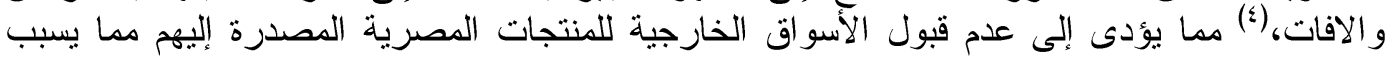

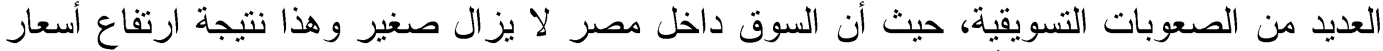

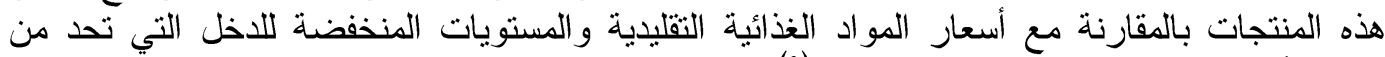

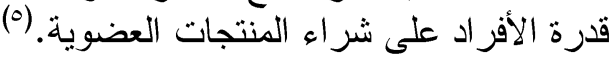

${ }^{1}$ ) FIBL, IFOAM, The World of Organic Agriculture Statistics And emerging trends, IFOAM Organic International, 2017, PP11-12.

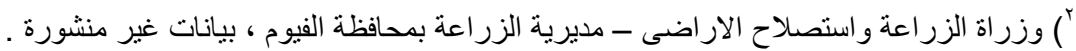

${ }^{3}$ )Boehlje, M.Dobbins, And others: Checking Your Farm Business Management Skills Purdue University, Agricultural Economics, 2001, pp2-6.

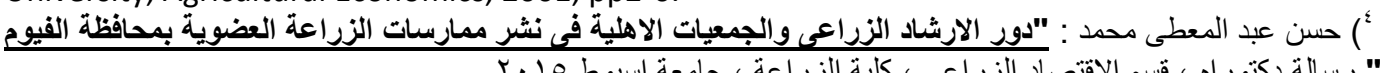

${ }^{5}$ ) Mohamed Abd A Ihmeda: Consumers` Motivations and Barriers towards organic food: the

Case of Egypt, International Journal of Economics and Business Modeling, India, 2010, 3(3), 180-

186

Fayoum J. Agric. Res. \& Dev., Vol. 33, No.2, July, 2019 
تستهدف الدراسة بصفة اساسية قياس أثر تطبيق انماط الادارة المزرعية على عمليتى انتاج

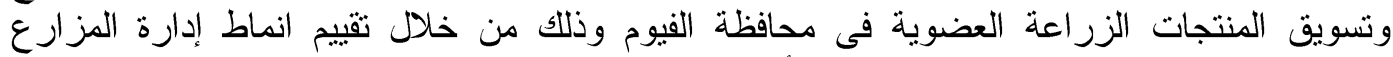

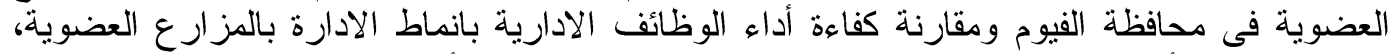

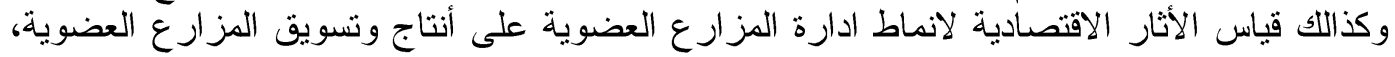

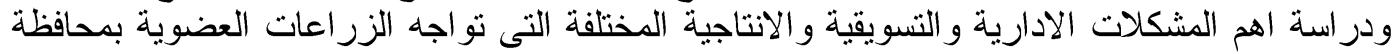

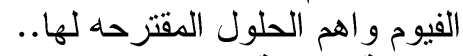
الطريقة البحثية ومصادر البيانات:

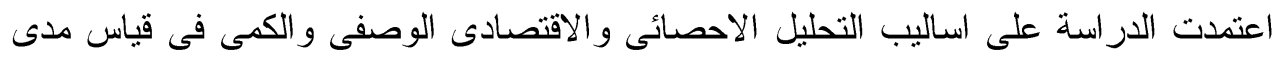

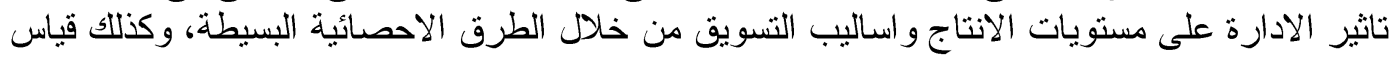

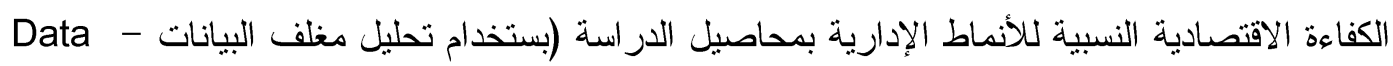
Envelopment Analysis - DEA

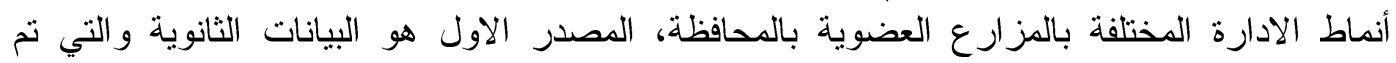

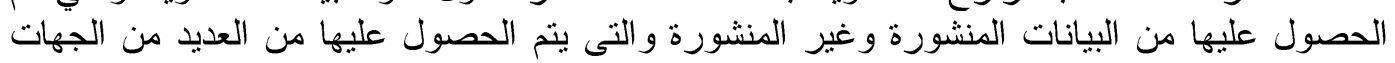

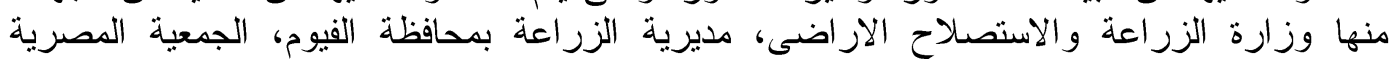

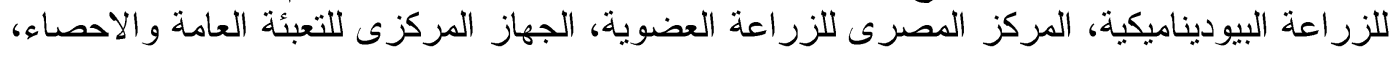

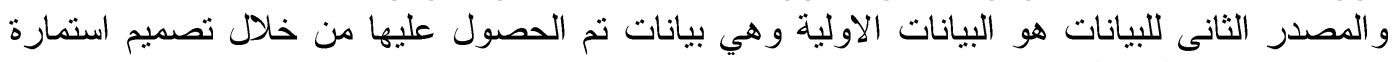

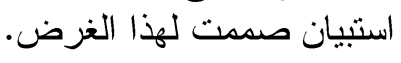

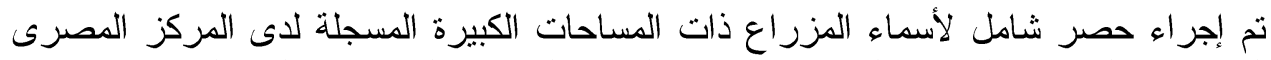

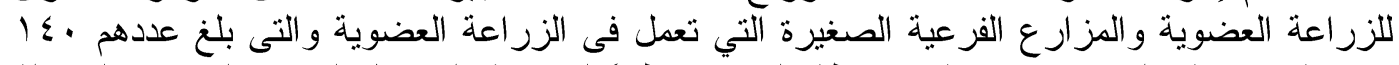

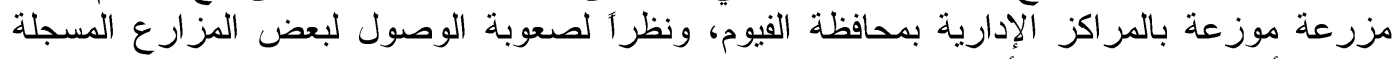

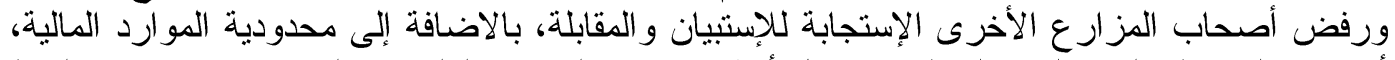

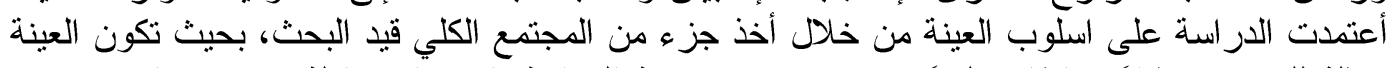

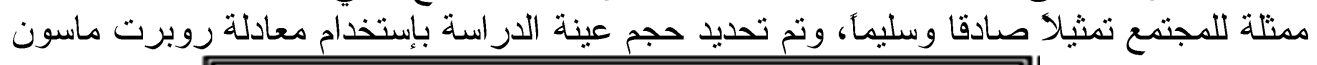
$n=\left[\left(s^{2} \times(N-1)\right) \div p q\right]+1$

ح

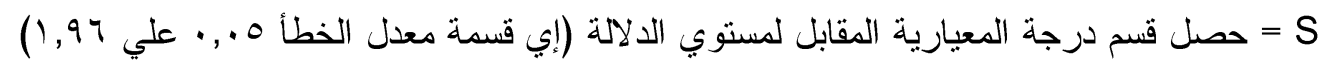

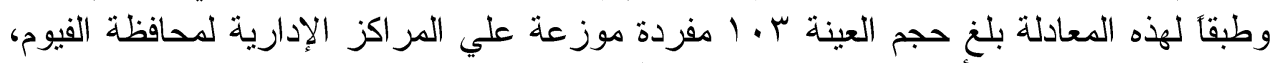

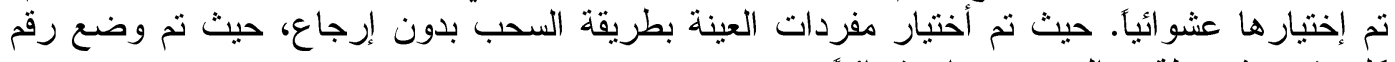
كل مفردة في سلة تم السحب منها عشو ائياً.

Fayoum J. Agric. Res. \& Dev., Vol. 33, No.2, July, 2019 


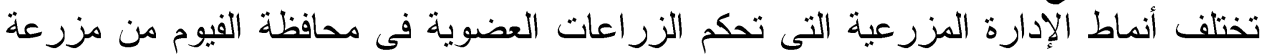

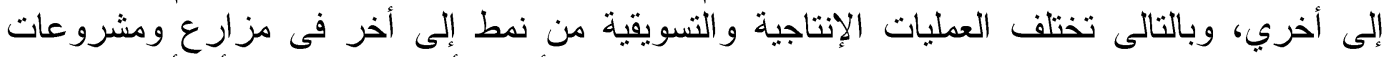

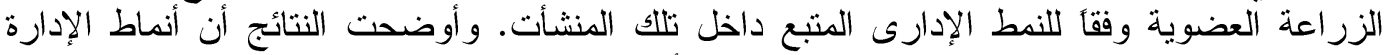

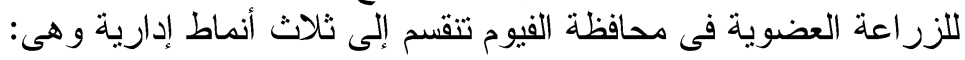

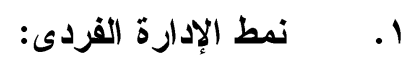

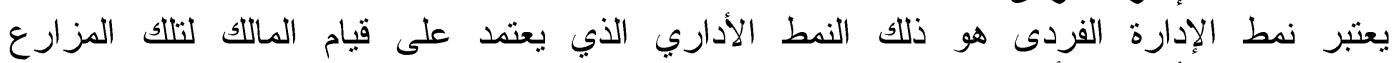

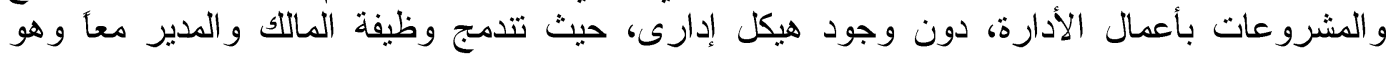

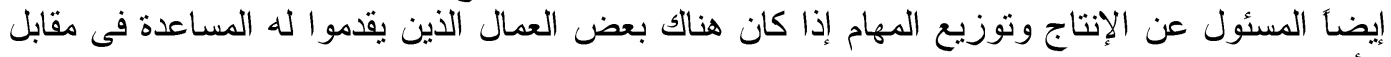

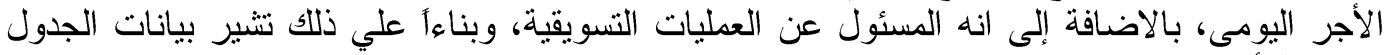

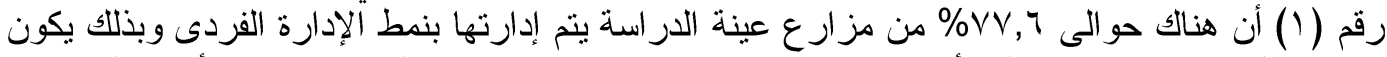

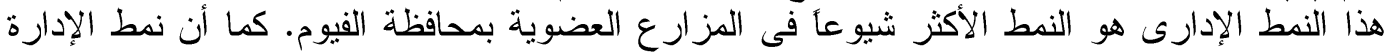
الفردى فى مزار ع الدر اسة ينقسم إلى نو عين من هما:

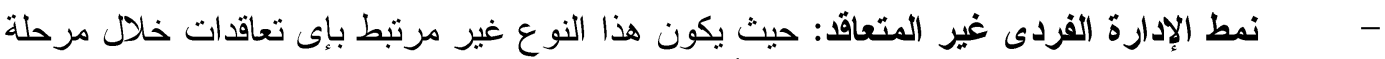

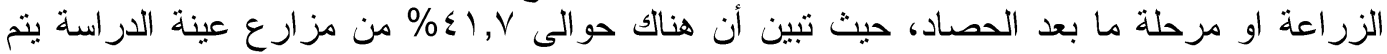

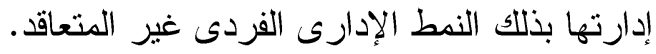

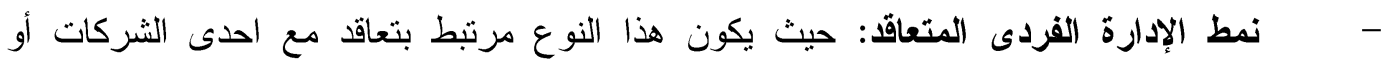

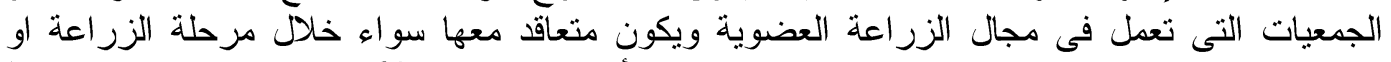

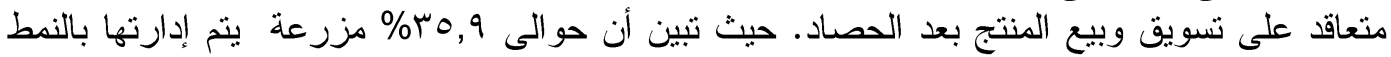

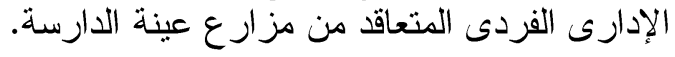

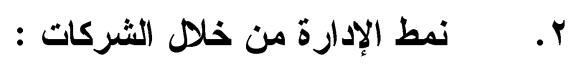

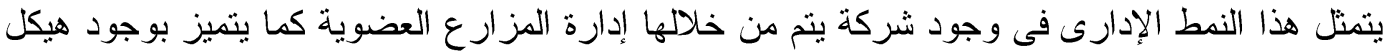

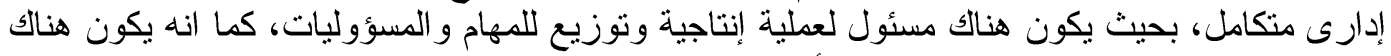

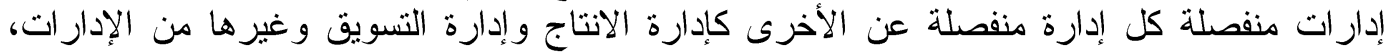

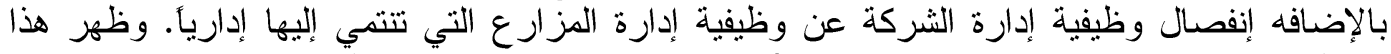

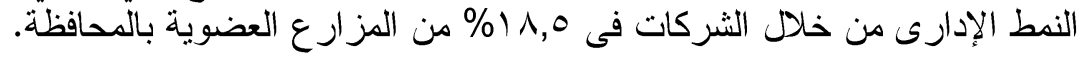

\section{r. نمط الإدارة التعاونى :}

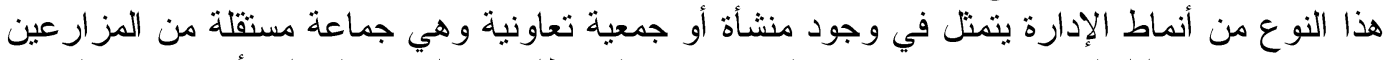

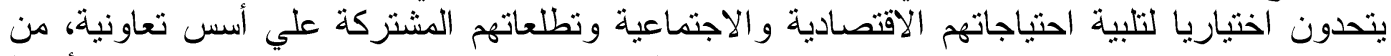

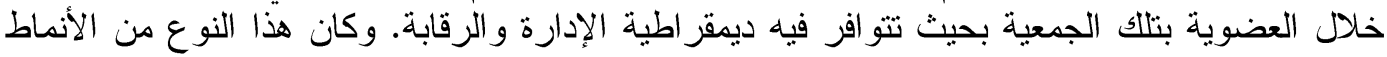

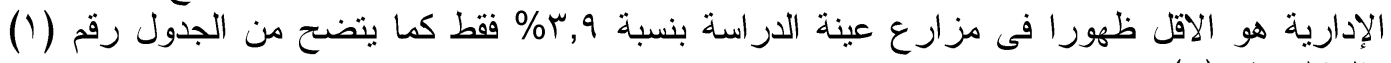

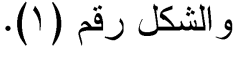

Fayoum J. Agric. Res. \& Dev., Vol. 33, No.2, July, 2019 
$17 \varepsilon$

جدول (1) : توزيع مزارع عينة الار اسة وفقاً للنمط الإدارى السائد

\begin{tabular}{|c|c|c|}
\hline$\%$ & التكر ارات & النمط الإدارى السائد \\
\hline$\xi 1, V$ & $\varepsilon r$ & نمط الإدارة الفردى غير المتعاقد \\
\hline ro, 9 & rV & نمط الإدارة الفردى المتعاقد \\
\hline 11,0 & 19 & نمط الإدارة من خلا الثركات \\
\hline$r, q$ & $\varepsilon$ & نمط الإدارة التعاونى \\
\hline $1 \ldots$ & $1 . r$ & الاجمالى \\
\hline
\end{tabular}

شكل رقم (1): توزيع مزارع عينة الارسة وققاً للنمط الإدارى السائد

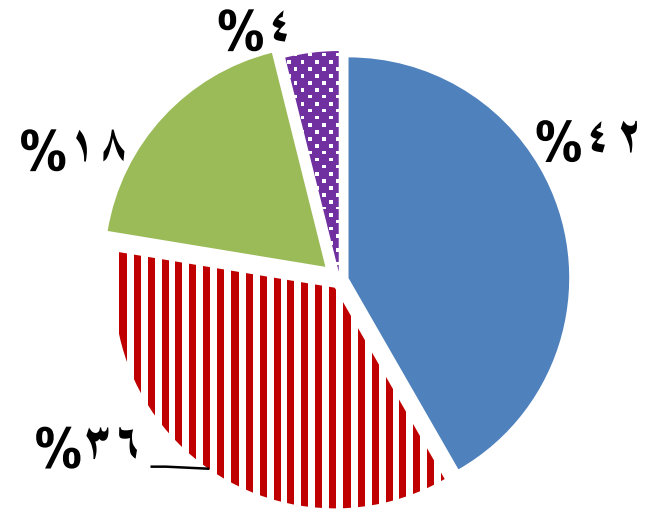

تظام الإدارة الفردى غير المتعاقد

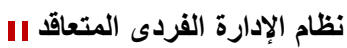

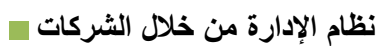

نظام الإدارة التعاونى هن

المصدر: جمعت وحببت من بيانات جدول رقم (1).

ثانياً: مؤشرات الكفاعة الإقتصادية لأنماط الادارة المزرعية فى المزارع العضوية

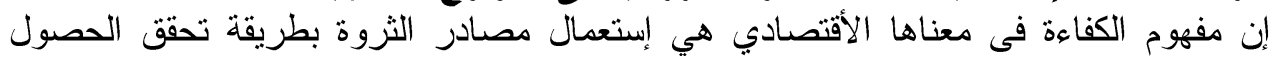

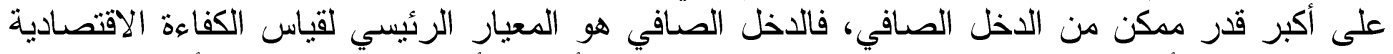

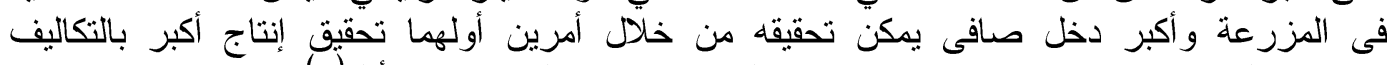

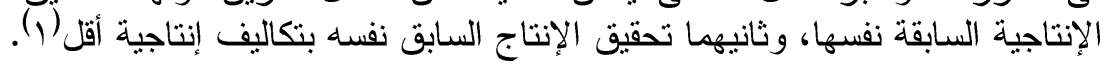

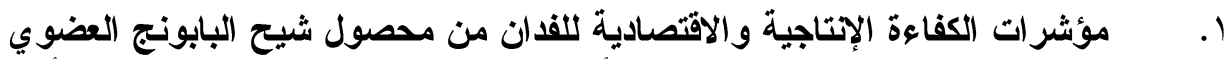

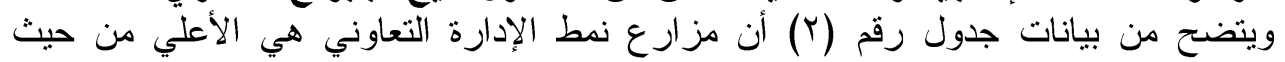

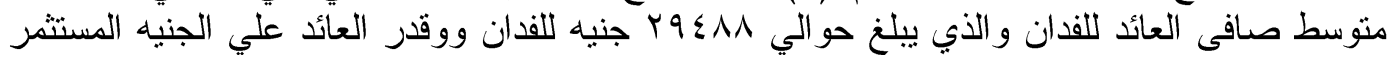

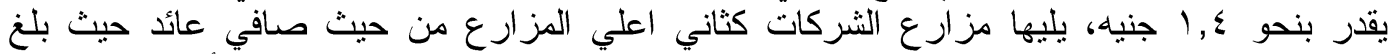

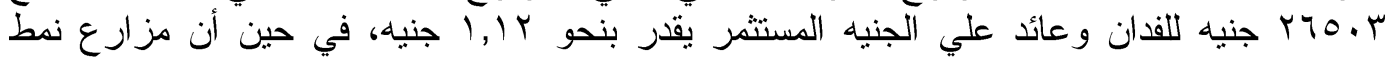

' ) هاثتم علون السامر ائى: إدارة الاعمال المزرعية، دار اليازورى العلمية للنشر والتوزيع، عمان، الاردن، الطبعة العربية،

Fayoum J. Agric. Res. \& Dev., Vol. 33, No.2, July, 2019

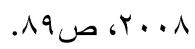


190

الإدارة الفردى غير المتعاقد (الني تقوم بمرحلة الإنتاج فقط) هي أقل المزارع من حيث صافي عائد

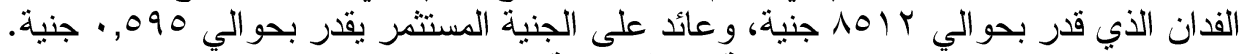
جدول (Y): مؤشرات ألكفاعة الإتتاجية والاقتصادية للقدان من محصول شيح البابونج العضوى بعينة

\begin{tabular}{|c|c|c|c|c|c|c|}
\hline \multirow{3}{*}{ تمط مز التعاونى الإدارة } & \multirow{3}{*}{ 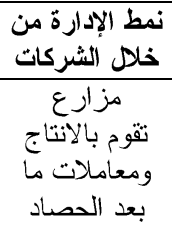 } & \multicolumn{4}{|c|}{ نمط الإدارة الفردى } & \multirow[b]{3}{*}{ البند البد } \\
\hline & & \multicolumn{2}{|c|}{ المتعاقا } & \multicolumn{2}{|c|}{ غير المتعاقد } & \\
\hline & & تعدم بالانتاج & تقوم بمرحلة الإنتاج فقط & 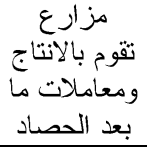 & تقوم بمرحلة الإنتاج فقط & \\
\hline Y.01Y & $r r \leqslant 9 V$ & YITVV & 17.04 & $r .04 q$ & $1 \leqslant Y 97$ & متوسط التكاليف الكلية (جنيه) \\
\hline $0 \ldots$ & $0 \ldots$ & $\varepsilon 0 \ldots$ & rorno & 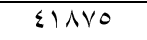 & YYA.A & متوسط الإيراد الكلي (جنيه) \\
\hline$r q \leqslant \Lambda \Lambda$ & rTo.r & THYTH & QTHT & (TוTH & NOIY & متوسط صافى العائد (جنيه) \\
\hline $1, \varepsilon$ & $1,1 r$ & 1,1 & $\cdot, 01$ & $1, \cdot \varepsilon$ & $\cdot, 090$ & العائد على الجنيه المستثمر \\
\hline Y.01Y & $r r \leqslant q V$ & TITVV & TAYT & TMT. & rrsq & تكلفة الطن (جنيه) \\
\hline
\end{tabular}

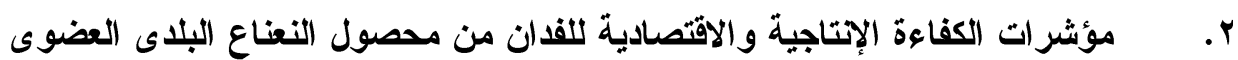

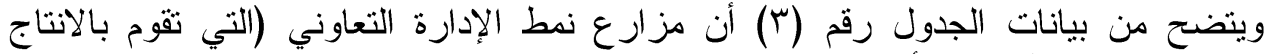

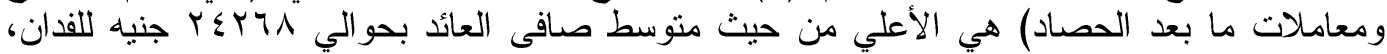

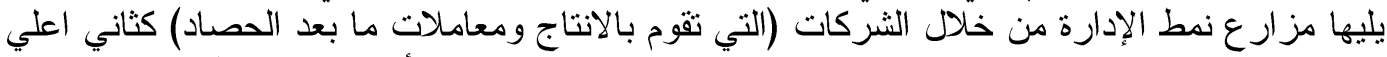

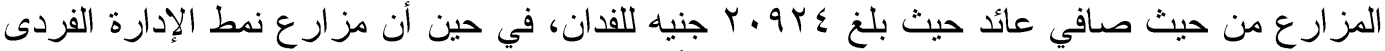

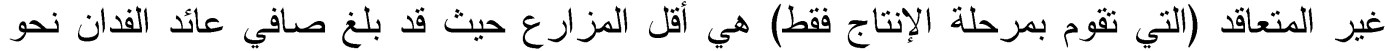

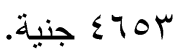

جدول (ץ): مؤشرات الكفاعة الإنتاجية والاقتصادية للقدان من محصول النعناع البلاى العضوى بعينة

\begin{tabular}{|c|c|c|c|c|c|c|}
\hline نمط الإدارة & نمط الإدارة من & & الفردى & نمط الإدار & & \\
\hline التعاونى & خلال ألشركات & تعاقد & & متعاقد & 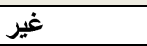 & \\
\hline ومعاملات بالانتاج ما بعد & 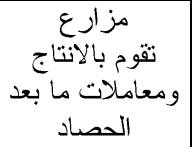 & تقوم بالانتاج & مز بقومارع & 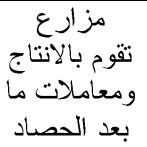 & تقوم بمرحلة & البند \\
\hline TYVTY & $Y Y \cdot V 4$ & $1 V T 17$ & $1.91 \mathrm{~V}$ & IAVTV & $17 \varepsilon 1 \varepsilon$ & متوسط التكاليف الكلية (جنيه) \\
\hline$\varepsilon V \ldots$ & $\varepsilon \vee \ldots$ & rVY.. & 1097. & rqY.. & $T 1 . T V$ & متوسط الإيراد الكلي (جنيه) \\
\hline$r \leq r Y A$ & r.9Yร & 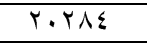 & $0 . \leqslant r$ & $r \cdot \Sigma V T$ & stor & متوسط صافى العائد (جنيه) \\
\hline $1, \cdot V$ & $\cdot, \wedge$ & $1,1 \mathrm{~V}$ & $\cdot, \leqslant 7$ & $1, .9$ & $\cdot, Y \wedge$ & العائد على الجنيه المستثمر \\
\hline 11147 & IT.TA & 97.. & $r q$. & $947 \leqslant$ & 100 & تكلفة الطن (جنيه) \\
\hline
\end{tabular}

أما من حيث العائد علي الجنيه المستثمر فإن مزارع نمط الإدارة الفردى المتعاقد (التي تقوم بالانتاج

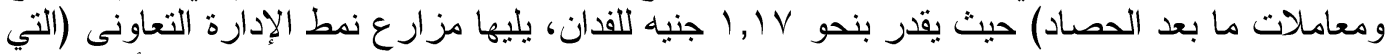

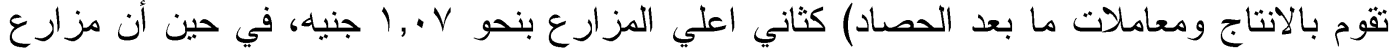

Fayoum J. Agric. Res. \& Dev., Vol. 33, No.2, July, 2019 
197

نمط الإدارة الفردى غير المتعاقد (التي تقوم بمرحلة الإنتاج فقط) هي أقل المزارع من حيث العائد على

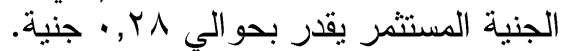

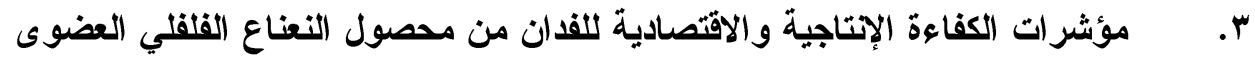

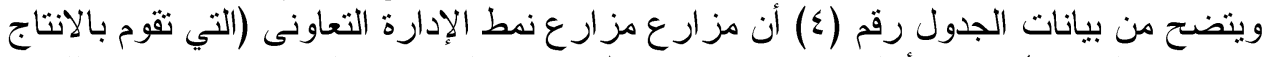

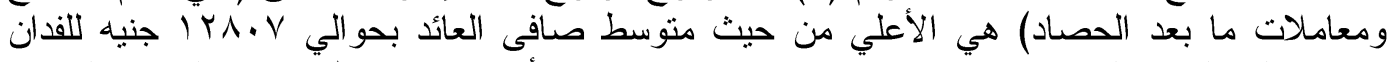

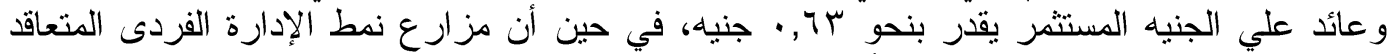

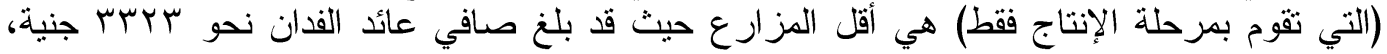

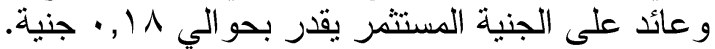

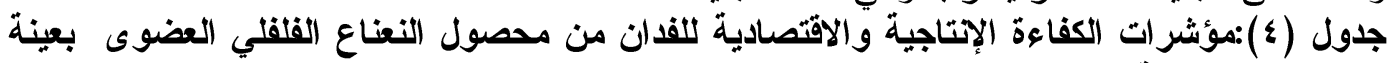

\begin{tabular}{|c|c|c|c|c|c|}
\hline \multirow{2}{*}{ نمط الإدارة } & \multirow{2}{*}{ خلا الثردات } & \multicolumn{3}{|c|}{ نمط الإدارة الفردى } & \multirow[b]{3}{*}{ البند } \\
\hline & & \multicolumn{2}{|c|}{ المتعاقد } & غير المتعاقا. & \\
\hline ومعامومات مالانتاج & تقوم بالانتاج & ومعاملات مالانتاج & تقوم بمزحطة الإنتاج فقط & ومعاملات بالانتاج ما بعد & \\
\hline$r .19 r$ & YMVTI & 19094 & 11.11 & rYOTK & متوسط التكاليف الكلية (جنيه) \\
\hline$r \mu \ldots$ & roro. & $r \ldots$. & YIr々 & r9人4 & متوسط الإيراد الكلي (جنيه) \\
\hline IYA.V & $11 \leqslant 19$ & $1 \cdot \varepsilon \cdot 1$ & TMTK & VY9A & متوسط صافى العائد (جنيه) \\
\hline 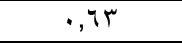 & $\cdot, \leqslant \wedge$ & •, or & $\cdot, 11$ & 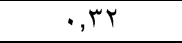 & العائد على الجنيه المستثمر \\
\hline IYSTY & $101 \varepsilon$. & $\mid r .71$ & $1 . .1$ & $10 . \leqslant Y$ & تكلفة الطن (جنيه) \\
\hline
\end{tabular}

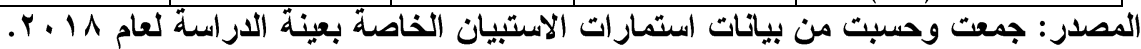

ثالثاً: قياس الكفاءة الاقتصادية النسبية للأنماط الإدارية بمحاصيل الاراسة

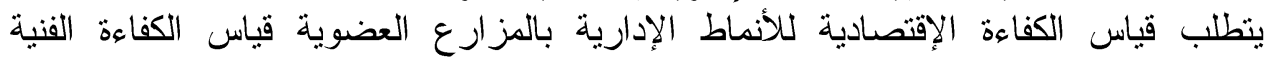
Technical Efficiency الكفاءة الفنية في حالة ثبات العائد على السعة (CRS) وفي حالة تغير العائد علي السعة (VRS)، وذللك

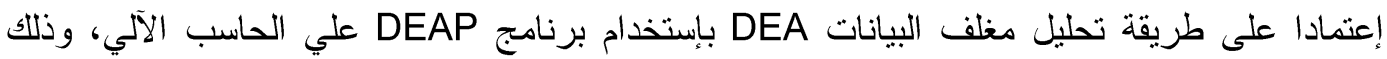

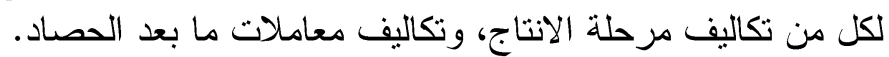

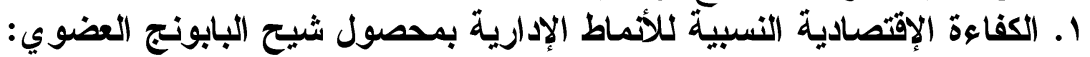

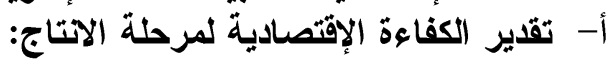

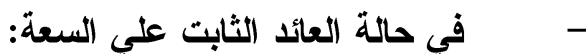
تشير بيانات جدول رقم (ْ) إلي الكفاءة الإقتصادية في حالة ثبات العائد علي السعة لتكاليف

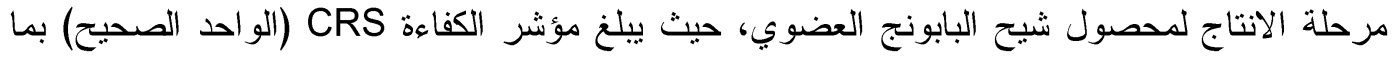

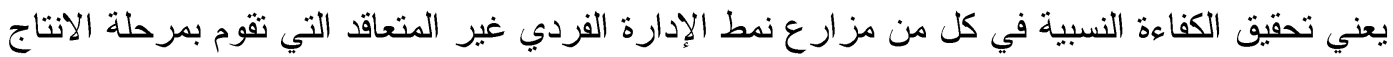

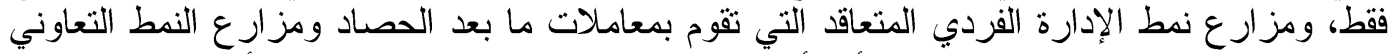
التي ثقوم بمعاملات ما بعد الحصاد، أي أنه تم إستغلال كافة المدخلات المتاحة بأفضل شكل مدكن

Fayoum J. Agric. Res. \& Dev., Vol. 33, No.2, July, 2019 
178

لتحقيق المخرجات وبالتالي تكون غلة الجحم ثابتة، أي ليس من المصلحة زيادة تكاليف مرحلة الانتاج، ويجب المحافظة على هذا المستوي من التكاليف.

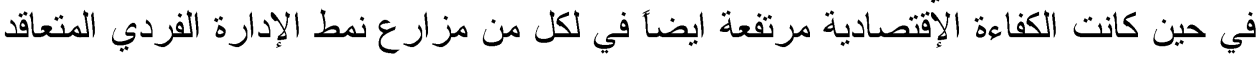

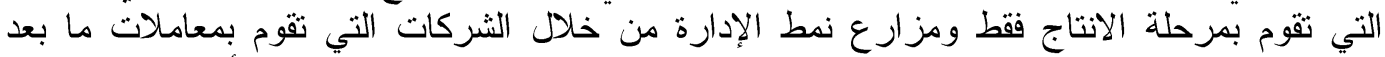

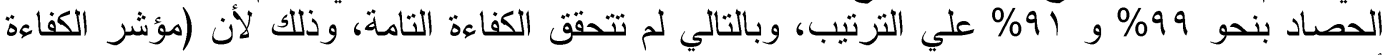
أقل من ()، وتكون غلة الحجم متتاقصة، لذلك هنالك حاجة إلي تخفيض تكاليف مرحلة الانتاج بكلا

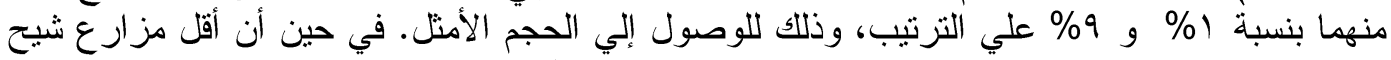

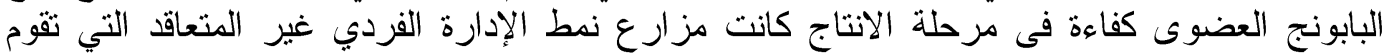

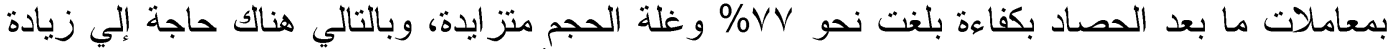
تكاليف مرحلة الانتاج بنسبة سبر ماد وذلك للوصول إلي الحجم الأمثل.

Fayoum J. Agric. Res. \& Dev., Vol. 33, No.2, July, 2019 
191

جدول (0) مؤشر الكفاءة الاقتصادية النسبية حسب التوجيه الإدخالي لنموذجي CRS، VRS لتكاليف مرحلة الاتتاج بالمزارع العضوية لمحصول شيح البابونج

\begin{tabular}{|c|c|c|c|c|c|c|}
\hline \multirow{2}{*}{ 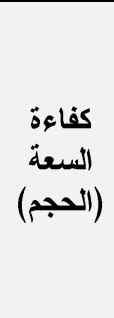 } & \multirow[b]{2}{*}{ غلة } & \multicolumn{2}{|c|}{ نموذج عوائد الحجم } & \multicolumn{2}{|c|}{$\begin{array}{c}\text { نموذج عوائد الحجم الثابت } \\
\text { (CRS) }\end{array}$} & \multirow{2}{*}{$\begin{array}{c}\text { مزارع النمط الإداري } \\
\text { (DMUs) }\end{array}$} \\
\hline & & مقدار & 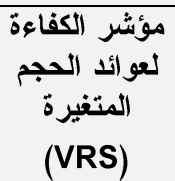 & مقدار & 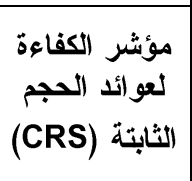 & \\
\hline 1 & ثابتة & - & 1 & • & 1 & 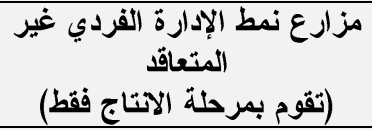 \\
\hline סשזו, • & متز ايدة & $\cdot, \cdot V \mid r$ & $\cdot, 9 \curlyvee \wedge \wedge$ & $\cdot, Y Y O \Lambda$ & $\cdot, V \vee \leq Y$ & مزارع نمط الإدارة الفردي غير \\
\hline$\cdot, 9997$ & متناقصة & • & 1 & $\cdot, \cdots \varepsilon$ & $\cdot, 9997$ & 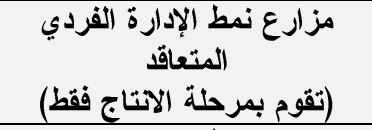 \\
\hline 1 & ثابتة & - & 1 & - & 1 & 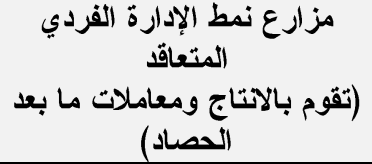 \\
\hline 1 & متناقصة & $\cdot, \cdot \wedge 99$ & $\cdot, 91 \cdot 1$ & $\cdot, 1199$ & $\cdot, 91 \cdot 1$ & 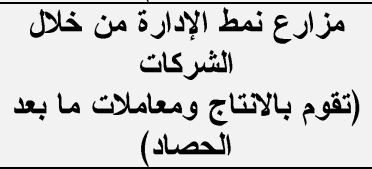 \\
\hline 1 & ثابتة & - & 1 & • & 1 & 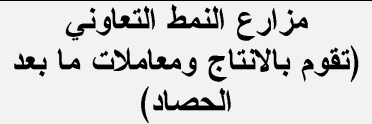 \\
\hline
\end{tabular}

كفاءة السعة (الحجم) = مؤشر الكفاءة لعوائد الحجم الثابتة (CRS) / مؤشر الكفاءة لعوائد الحجم المتغيرة (VRS)

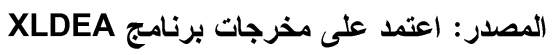

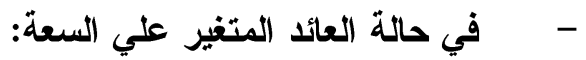

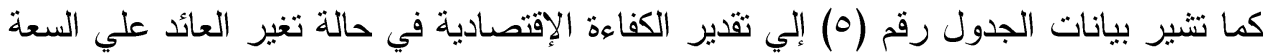

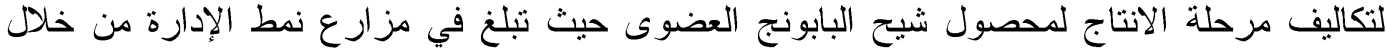

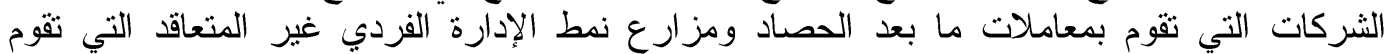

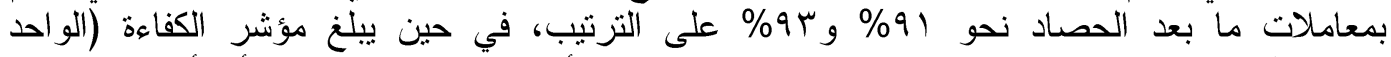

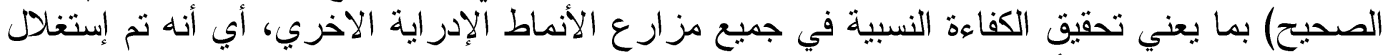
كافة المدخلات المتاحة بأفضل شكل ممكن لتحقيق المخرجات، وبالتالي لا يوجد النالئ عدم كفاءة.

Fayoum J. Agric. Res. \& Dev., Vol. 33, No.2, July, 2019 


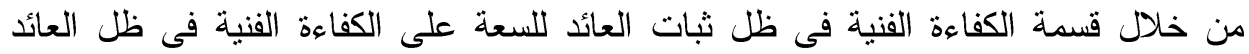

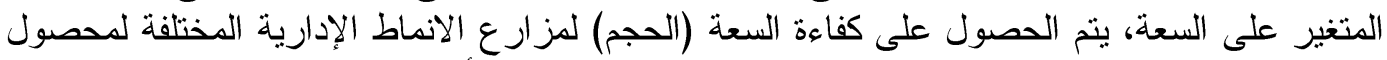

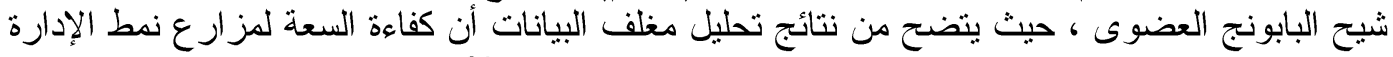

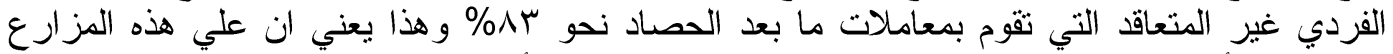

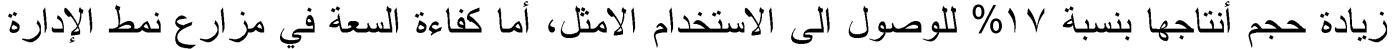

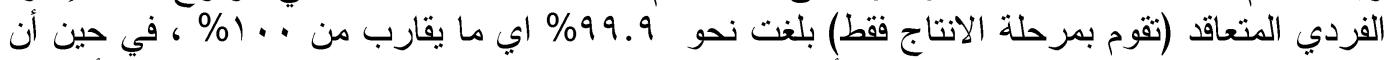

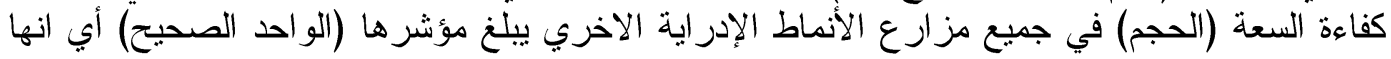

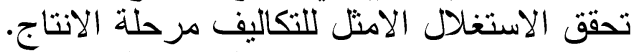

ب- تقدير الكفاءة الإقتصادية لمرحلة ما بعد الإلة الحصاد (معاملات ما بعد الحصاد):

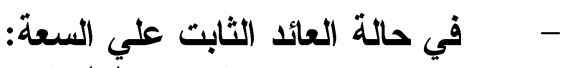

تشير بيانات جدول رقم (َ) إلي الكفاءة الإقتصادية في حالة ثبات العائد علي السعة لتكاليف

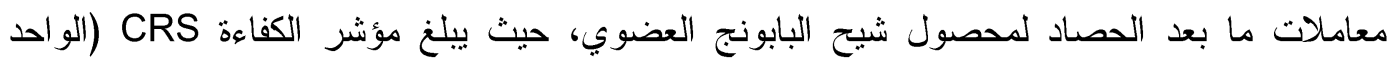

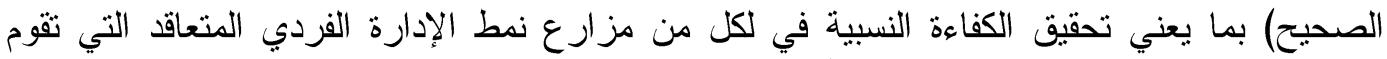

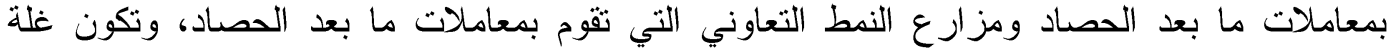

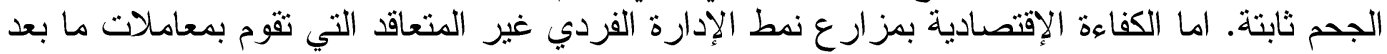

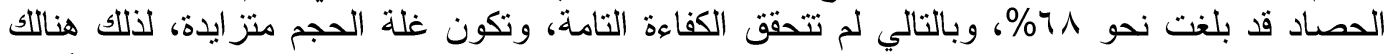

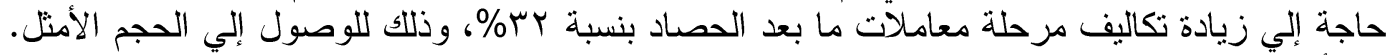

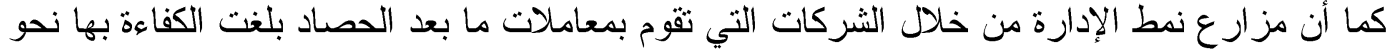
\%VY . \% rᄉ

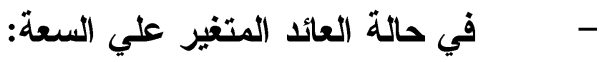

كما تشير بيانات الجدول رقم (؟) إلي تقدير الكفاءة الإقتصادية في حالة تغير العائد علي السعة

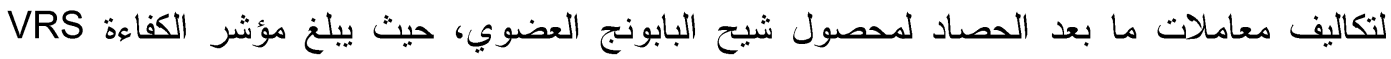

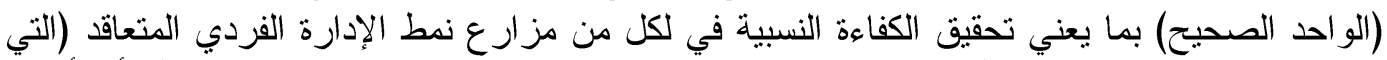

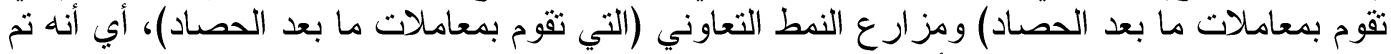

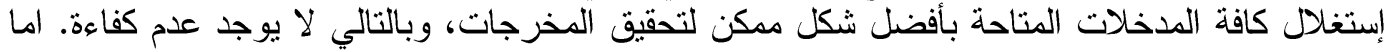

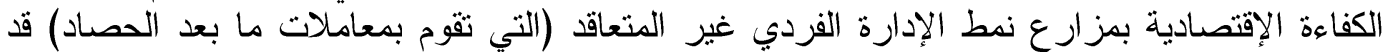

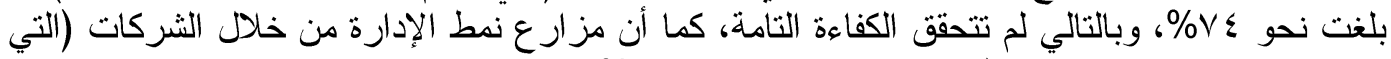

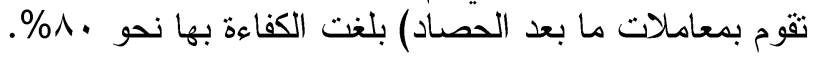

Fayoum J. Agric. Res. \& Dev., Vol. 33, No.2, July, 2019 
$1 \mathrm{~V}$

جدول (†) مؤشر الكفاعة الاقتصادية النسبية حسب التوجيه الإدخالي لنموذجي VRS، CRS، لتكاليف

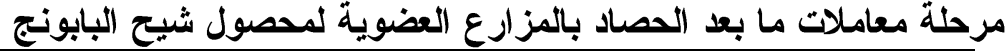

\begin{tabular}{|c|c|c|c|c|c|c|}
\hline \multirow[b]{2}{*}{ كفاعة السعة } & \multirow[b]{2}{*}{ غلثة } & \multicolumn{2}{|c|}{$\begin{array}{c}\text { نموذج عوائد الحجم المتغير } \\
\text { (VRS) }\end{array}$} & \multicolumn{2}{|c|}{$\begin{array}{c}\text { نموذج عوائد الحجم الثابث } \\
\text { (CRS) }\end{array}$} & \multirow{2}{*}{$\begin{array}{c}\text { مزارع النمط الإداري } \\
\text { (DMUs) }\end{array}$} \\
\hline & & مقدار عدم الكفاعة & 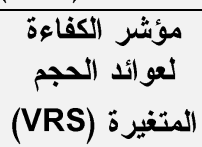 & مقدار عدم الكفاعة & 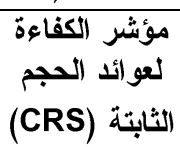 & \\
\hline זrr, • & متز ايدة &.,$r 090$ & $\cdot, V \leq .0$ & rד וז, • & $\cdot, Y \wedge \mu V$ & مزارع نمط الإدارة الفردي غير \\
\hline 1 & ثابتة & - & 1 & • & 1 & 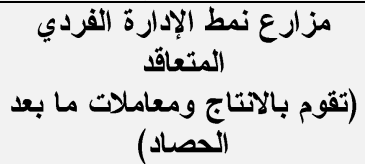 \\
\hline •, А९ץ & متناقصة & $\cdot, 19 r \wedge$ & $\cdot, \Lambda \cdot V Y$ & $\cdot, Y \vee \wedge \vee$ & •,VYIT & (تقوم بالاتناج ومعاملات ما الشركات الإدة من خلاد \\
\hline 1 & ثابتة & • & 1 & • & 1 & (تقوم بالاتتاج ومعاملات مـا بعد التعاوني \\
\hline
\end{tabular}

كفاءة السعة (الحجم) = مؤشر الكفاعة لعو ائد العجم الثابتة (CRS) / مؤشر الكفاءة لعوائد الحجم المتغيرة (VRS)

المصدر: اعتمد على مخرجات برنامج عLDEA

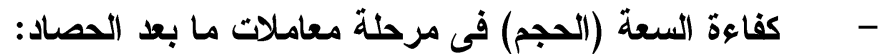

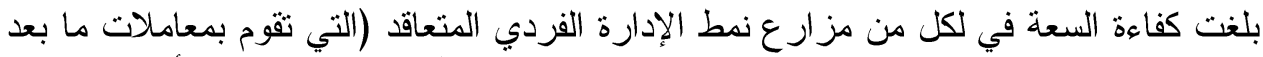

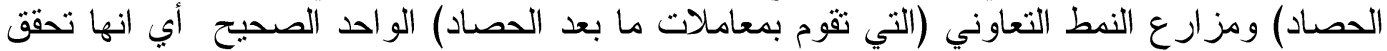

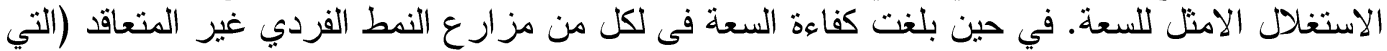

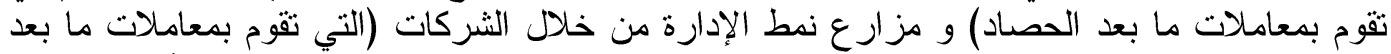

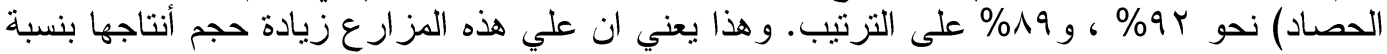

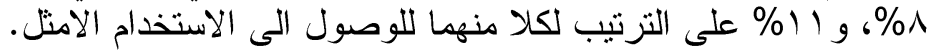

Fayoum J. Agric. Res. \& Dev., Vol. 33, No.2, July, 2019 
r ـ الكثاعة الإقتصادية النسبية للأنماط الإدارية بمحصول النعناع البلايى العضوى :

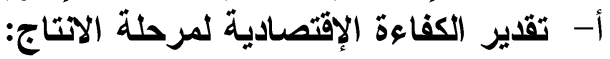

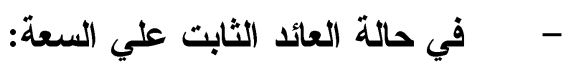

تشير بيانات جدول رقم (V) إلي الكفاءة الإقتصادية في حالة ثبات العائد علي السعة لتكاليف

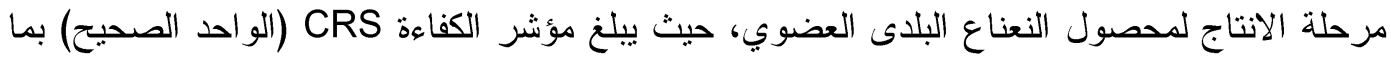

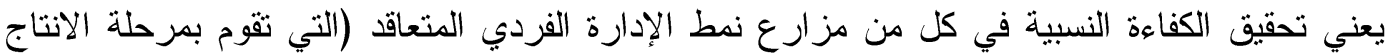

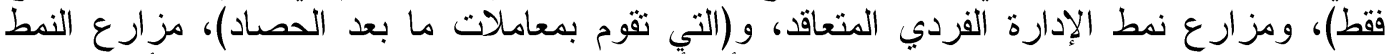

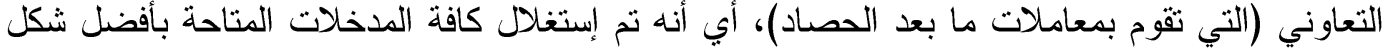

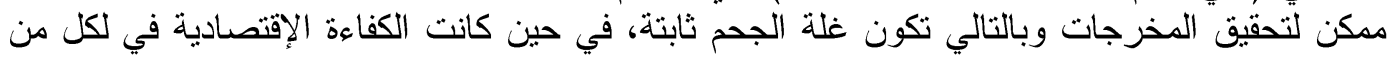

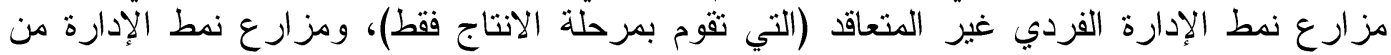

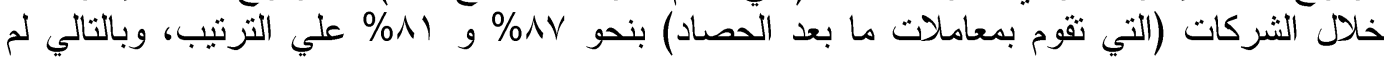

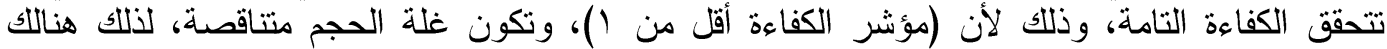

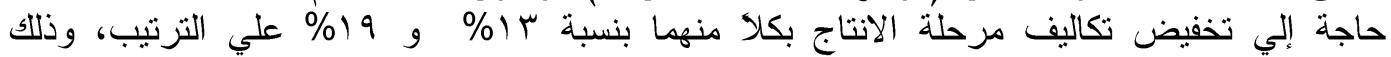

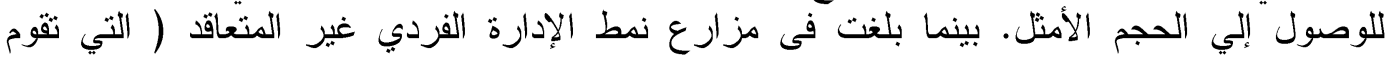

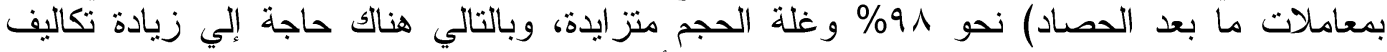

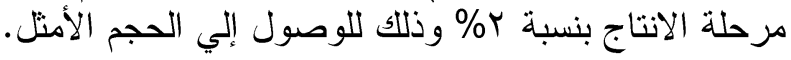

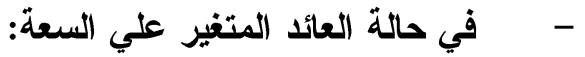

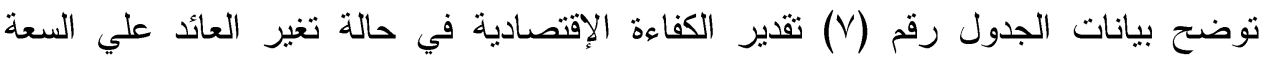

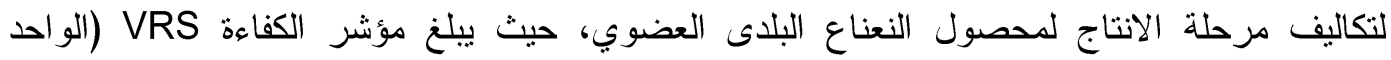

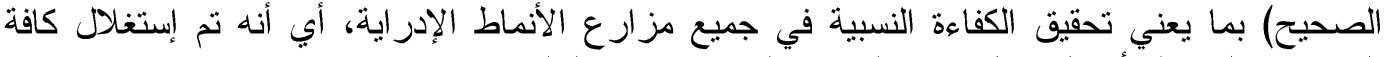

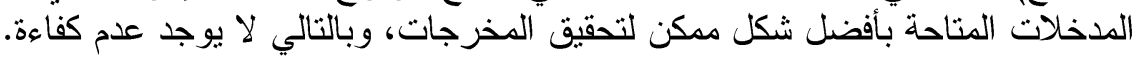

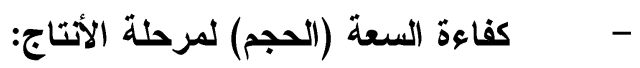

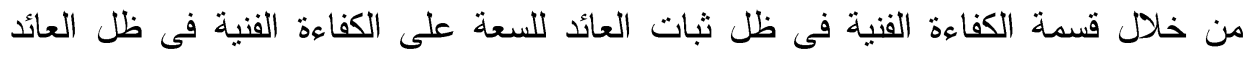

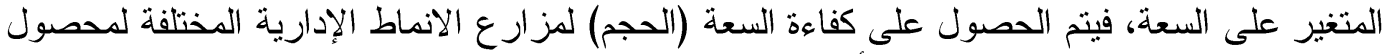

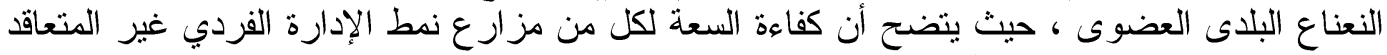

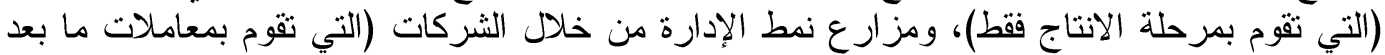

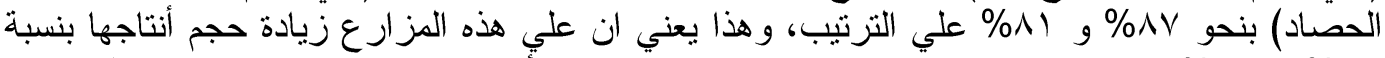

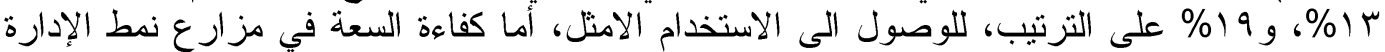

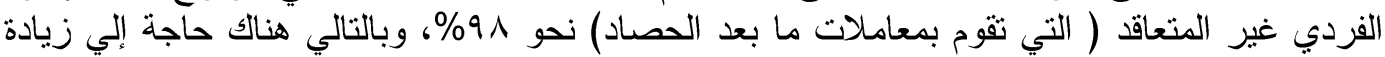

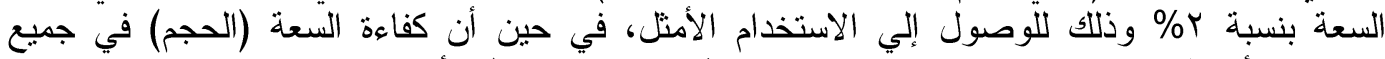
مزارع الأنماط الإدراية الاخري ييلغ مؤشرها (الواحد الصحيح)، أي انها تحقق الاستغلال الامتل

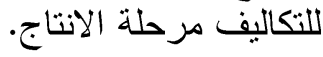

Fayoum J. Agric. Res. \& Dev., Vol. 33, No.2, July, 2019 
IVr

جدول (V) مؤثر الكفاعة الاقتصادية النسبية حسب التوجيه الإدخالي لنموذجي VRS CRS لتكاليف

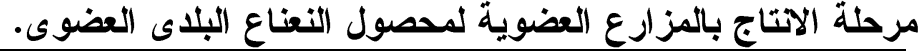

\begin{tabular}{|c|c|c|c|c|c|c|}
\hline \multirow{2}{*}{$\begin{array}{l}\text { (السعاءة } \\
\text { (الحجم) }\end{array}$} & \multirow{2}{*}{ 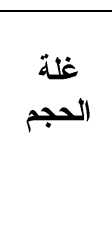 } & \multicolumn{2}{|c|}{$\begin{array}{c}\text { نموذج عوائد الحجم المتغير } \\
\text { (VRS) }\end{array}$} & \multicolumn{2}{|c|}{$\begin{array}{c}\text { نموذج عوائد الحجم الثابت } \\
\text { (CRS) }\end{array}$} & \multirow{2}{*}{$\begin{array}{l}\text { مزارع النمط الإداري } \\
\text { (DMUs) }\end{array}$} \\
\hline & & مقار & المؤشر الكفاءة & مقارار عدام & 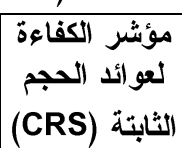 & \\
\hline$\cdot, \wedge \vee \vee q$ & متناقصة & . & 1 & $\cdot|Y Y|$ & $\cdot, \wedge \vee \vee q$ & $\begin{array}{c}\text { مزارع نمط الإدارة الفردي غئد } \\
\text { (تقوم بمرحة الآتاج فقط) }\end{array}$ \\
\hline$\cdot, q \wedge \uparrow q$ & متز ايدة & . & 1 & $\cdot, \cdot|V|$ & 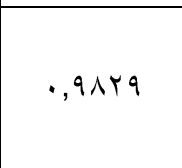 & 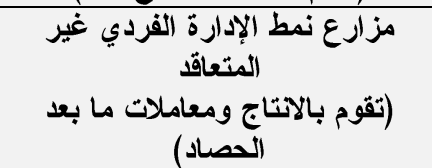 \\
\hline 1 & ثابتة & . & 1 & . & 1 & 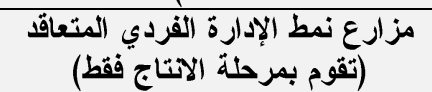 \\
\hline 1 & ثابتة & . & 1 & . & 1 & 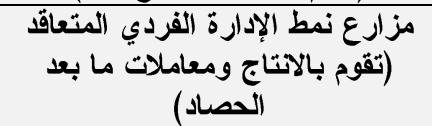 \\
\hline & متناقصة & . & 1 & •, 1Ат4 & گ & 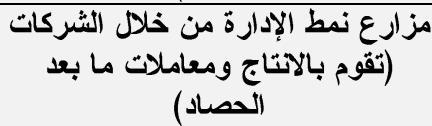 \\
\hline 1 & ثابتة & . & 1 & . & 1 & 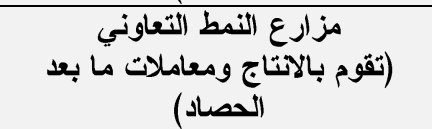 \\
\hline
\end{tabular}

كفاءة السعة (الحجم) = مؤشر الكفاءة لعوائد الحجم الثابتة (CRS) / مؤشر الكفاعة لعوائد الحجم المتغيرة (VRS)

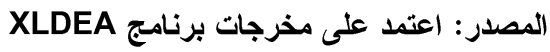

ب- - تقدير الكفاعة الإقتصادية لمرحلة ما بعد الحصاد (معاملات ما بعد الحصاد): في حالة العائد الثابت علي السعة:

تثير بيانات جدول رقم (م) إلي الكفاءة الإقتصادية في حالة ثبات العائد علي السعة لتكاليف معاملات

ما بعد الحصاد لمحصول النعناع البلدى العضوي، حيث يبلغ مؤشر الكفاءة CRS (الواحد الصحيح) بما يعني

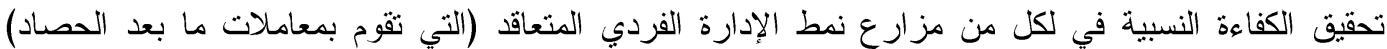

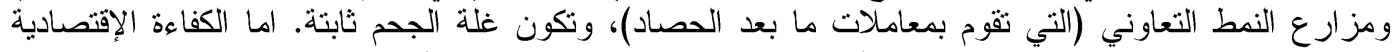

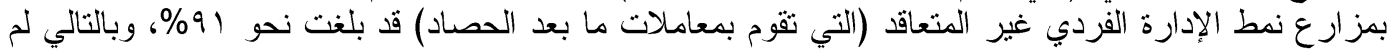

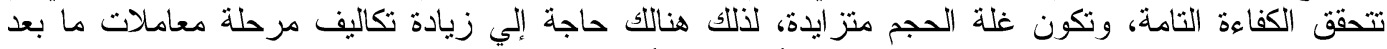

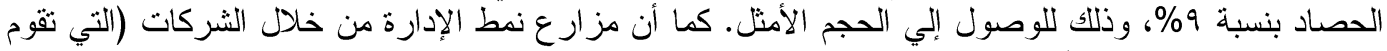

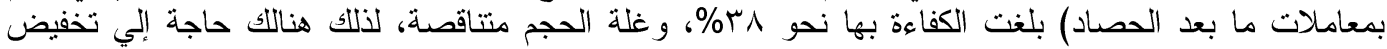

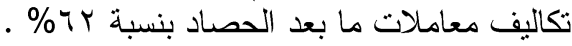

Fayoum J. Agric. Res. \& Dev., Vol. 33, No.2, July, 2019 
IVr

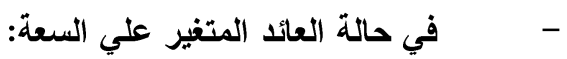

كما تشير بيانات الجدول رقم (^) إلي تقدير الكفاءة الإقتصادية في حالة تغير العائد علي السعة لتكاليف

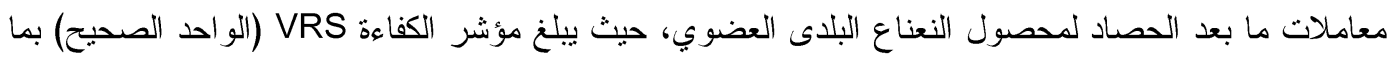

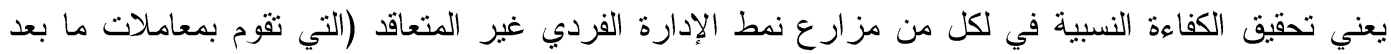

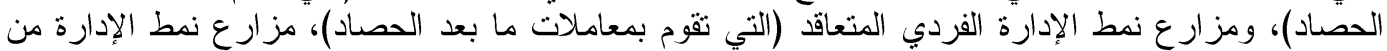

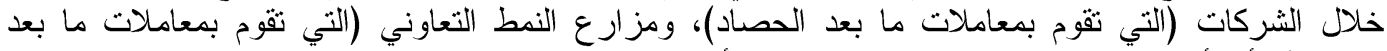

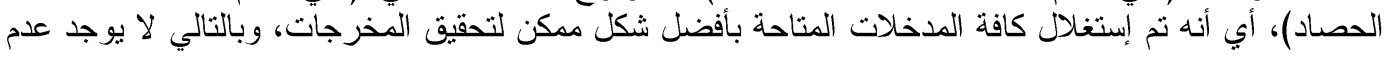

كفاعة السعة (الحجم) فى مرحلة معاملات ما بعد الحصاد:

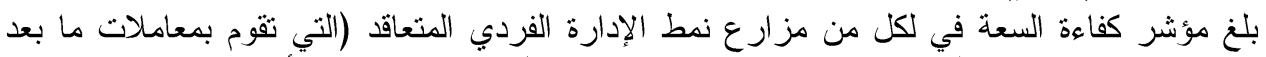

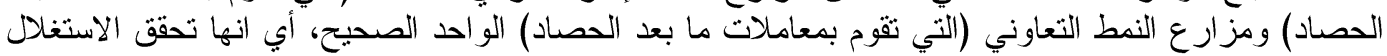

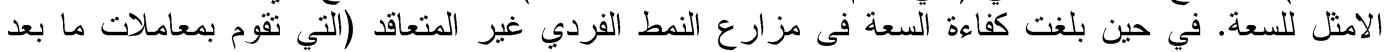

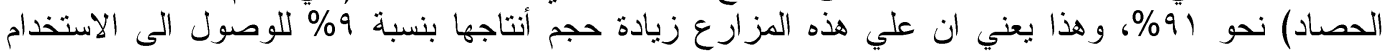

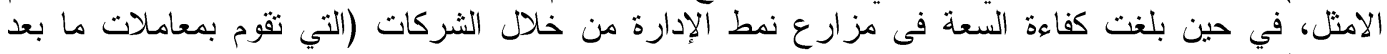

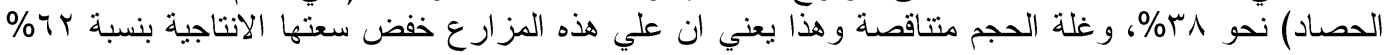

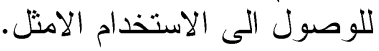

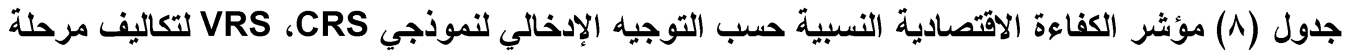

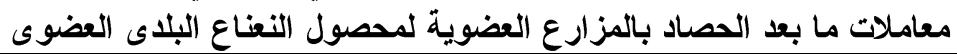

\begin{tabular}{|c|c|c|c|c|c|c|}
\hline \multirow{2}{*}{ كفاءة (السعة } & \multirow[b]{2}{*}{ غلة الحجم } & \multicolumn{2}{|c|}{$\begin{array}{c}\text { نموذج عوائد الحجم المتغير } \\
\text { (VRS) }\end{array}$} & \multicolumn{2}{|c|}{$\begin{array}{c}\text { نموذج عوائد الحجم الثابت } \\
\text { (CRS) }\end{array}$} & \multirow{2}{*}{$\begin{array}{l}\text { مزارع النمط الإداري } \\
\text { (DMUs) }\end{array}$} \\
\hline & & مقار عدام & $\mid \begin{array}{c}\mid \text { مؤشر الكفاعة الحجم المتغيرة } \\
\text { (VRS) }\end{array}$ & مقار عدام & العوائد الحجم الكفاءة & \\
\hline$\cdot, 9 \backslash \wedge \Lambda$ & متز ايدة & . & 1 & r., & $\cdot, 9 \backslash \wedge \wedge$ & 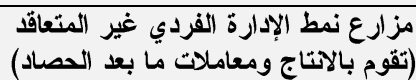 \\
\hline 1 & ثابتة & . & 1 & • & 1 & (تقوم بالآنتاج ومعاملات ما بادارة الفرد المصاداد) \\
\hline - rNOr & متناقصة & - & 1 & $\cdot, \pi) \leqslant 1$ & $\cdot, r \wedge \circ r$ & 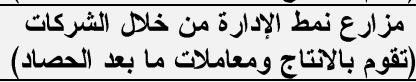 \\
\hline 1 & ثابتة & . & 1 & . & 1 & (تقوم بالانتاج ومعاملات ما بعد الحصاد) \\
\hline
\end{tabular}

كفاءة السعة (الحجم) = مؤشر الكفاعة لعوائد الحجم الثابتة (CRS) / مؤشر الكفاعة لعوائد الحجم المتغيرة (VRS)

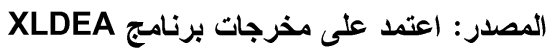

r. الكفاعة الإقتصادية النسبية للأنماط الإدارية بمحصول النعناع القلقلي العضوى :

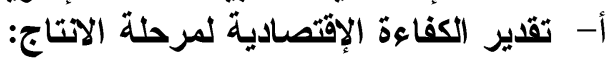

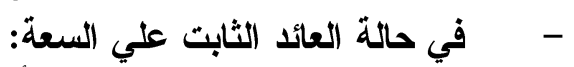
تشير بيانات جدول رقم (9) إلي أن الكفاءة الإقتصادية في حالة ثبات العائد العائد علي السعة لتكاليف

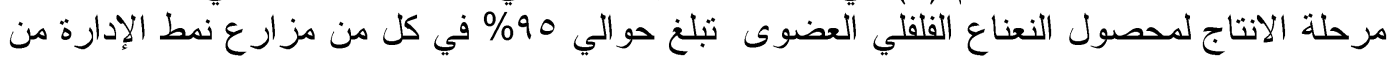

Fayoum J. Agric. Res. \& Dev., Vol. 33, No.2, July, 2019 
IV $\varepsilon$

خلال الثركات (التي تقوم بمعاملات ما بعد الحصاد) وبالتالي لم تتحقق الكفاءة التامة، وذلك لأن ألتأن (مؤشر

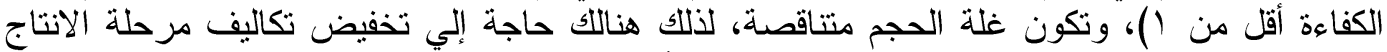

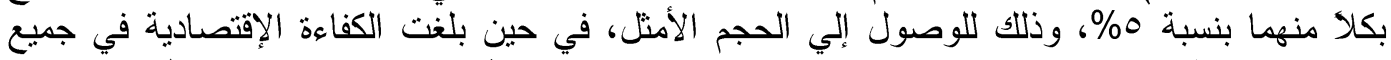

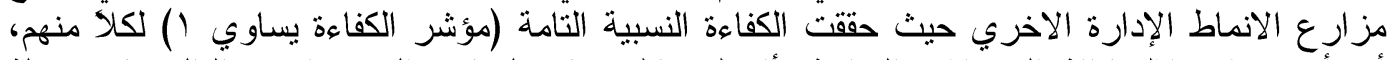

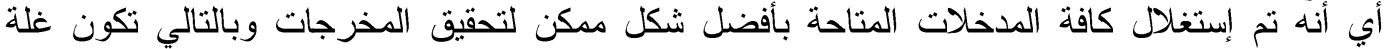

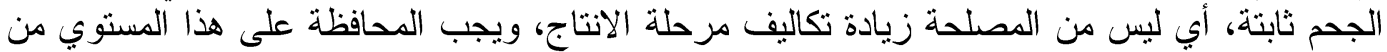

التكاليف.

\section{- - مي مالة العائد المتغير علي السعة:}

كما تشير بيانات الجدول رقم (9) إلي تقدير الكفاءة الإقتصادية في حالة تغير العائد علي السعة

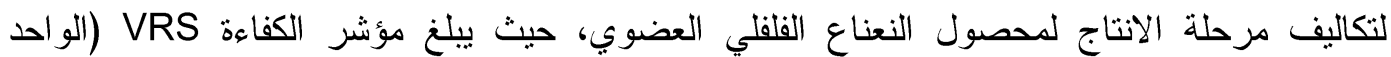

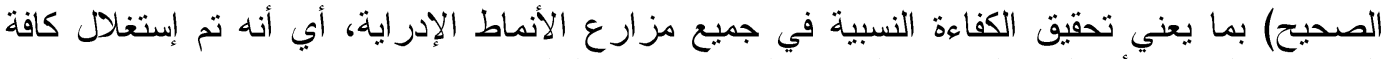

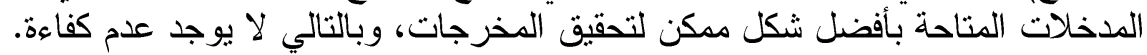

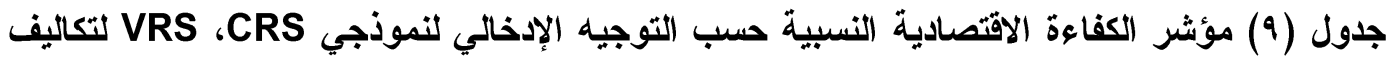

\begin{tabular}{|c|c|c|c|c|c|c|}
\hline \multirow[b]{2}{*}{ 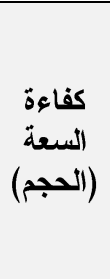 } & \multirow[b]{2}{*}{ غلمجة } & \multicolumn{2}{|c|}{$\begin{array}{c}\text { نموذج عوائد الحجم المتغير } \\
\text { (VRS) }\end{array}$} & \multicolumn{2}{|c|}{$\begin{array}{c}\text { نموذج عوائد الحجم الثابت } \\
\text { (CRS) }\end{array}$} & \multirow[b]{2}{*}{$\begin{array}{l}\text { مزارع النمط الإداري } \\
\text { (DMUs) }\end{array}$} \\
\hline & & مقدار عدم الكفاعة & لعونشر الأكفاعة الحجم & مقدار عدم الكفاعة & 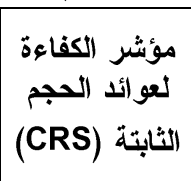 & \\
\hline 1 & ثابتة & . & 1 & - & 1 & 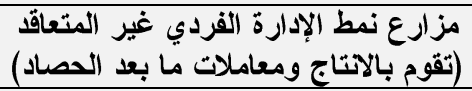 \\
\hline 1 & ثابتة & - & 1 & - & 1 & 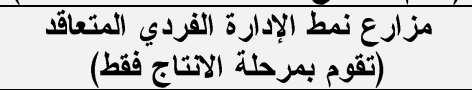 \\
\hline 1 & ثابتة & - & 1 & - & 1 & 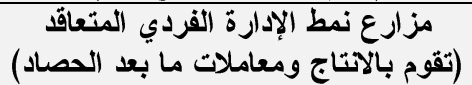 \\
\hline$\cdot, 9 \leq T V$ & متتاقصة & • & 1 & سזه., . & $\cdot, 9 \leq T V$ & 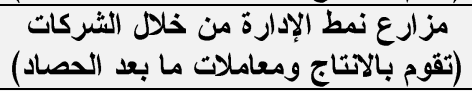 \\
\hline 1 & ثابتة & - & 1 & • & 1 & (تقوم بالانتاج ومعاملات مارع النعد الحصاد) \\
\hline
\end{tabular}

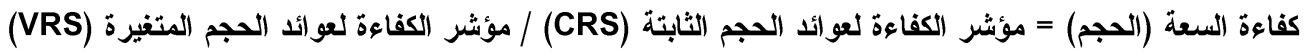

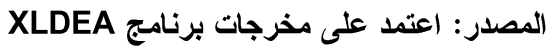
كفاعة السعة (الحجم) لمرحلة الأنتاج:

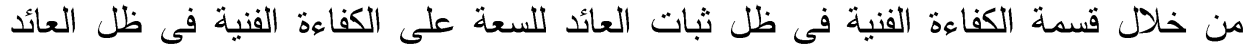

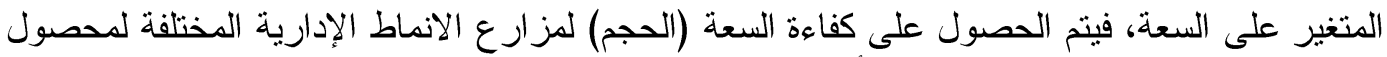

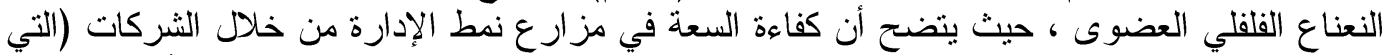

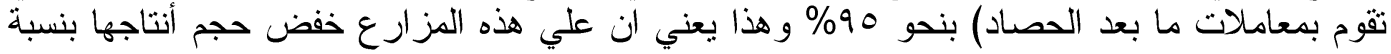

Fayoum J. Agric. Res. \& Dev., Vol. 33, No.2, July, 2019 
IVo

٪\%، للوصول الى الاستخدام الامثل، في حين أن كفاءة السعة (الحجم) في جميع مزار ع الأنماط الإدراية

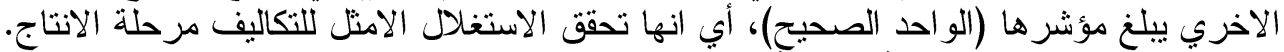

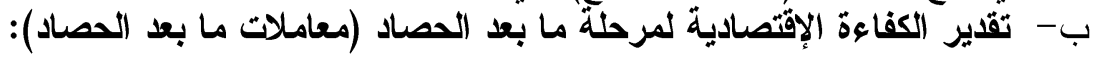

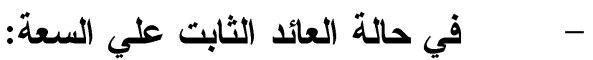
تشير بيانات جدول رقم (". (1) إلي الكفاءة الإقتصادية في حالة ثبات العائد علي السعة لتكاليف

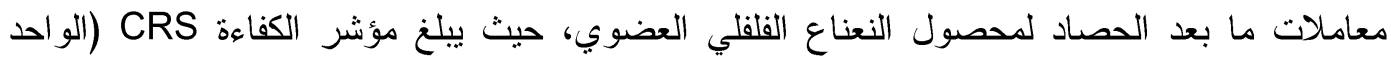

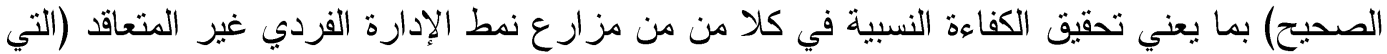

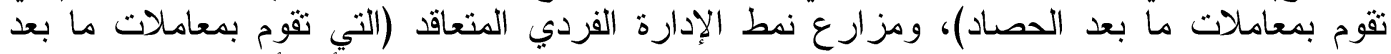

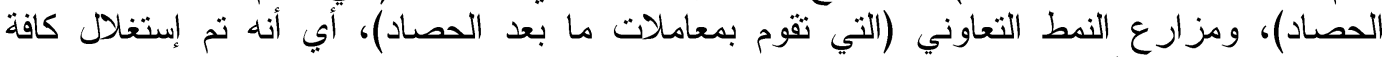

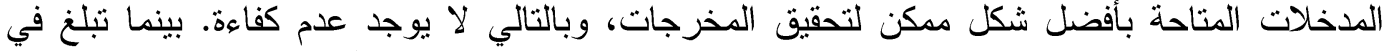

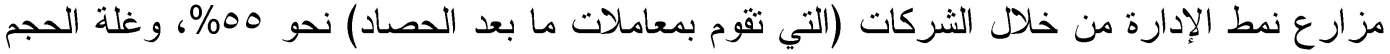

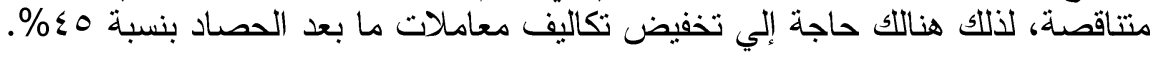

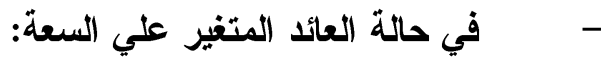

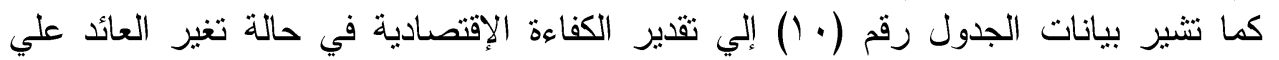
السعة لتكاليف معاملات ما بعد الحصاد لمحصول النعناع الفلفلي العضوي، حيث ييلغ مؤشر الكفاءة

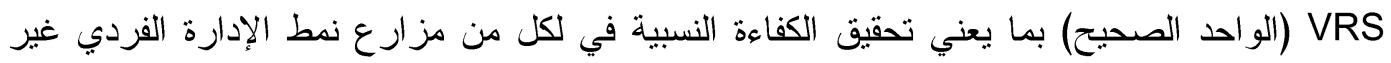

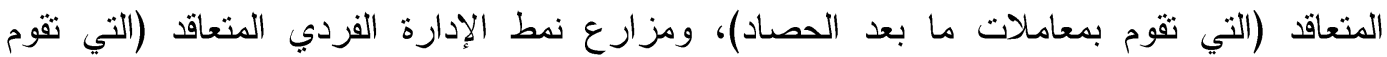

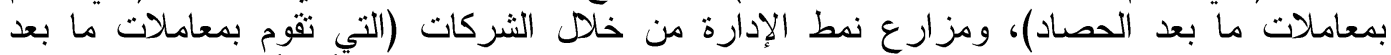

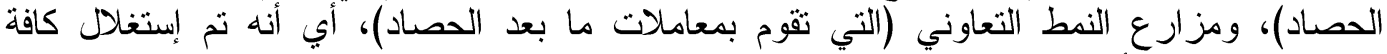
المدخلات المتاحة بأفضل شكل ممكن لتحقيق المخرجات، وبالتالي لا يومد بـد عدم كفاءة.

Fayoum J. Agric. Res. \& Dev., Vol. 33, No.2, July, 2019 
$1 \vee T$

جدول (· 1) مؤشر الكفاءة الاقتصادية النسبية حسب التوجيه الإدخالي لنموذجي CRS،

\begin{tabular}{|c|c|c|c|c|c|c|}
\hline \multirow[b]{2}{*}{ كفاءة السعة } & \multirow[b]{2}{*}{ غلة } & \multicolumn{2}{|c|}{$\begin{array}{c}\text { نموذج عو ائد الحجم المتغير } \\
\text { (VRS) }\end{array}$} & \multicolumn{2}{|c|}{$\begin{array}{l}\text { نموذج عوائد الحجم الثابت } \\
\text { (CRS) }\end{array}$} & \multirow[b]{2}{*}{$\begin{array}{l}\text { مزارع النمط الإداري } \\
\text { (DMUs) }\end{array}$} \\
\hline & & مقدار عدام & لعؤشر الكفائد & مقدار عدام & لثوأشر الكفاءة & \\
\hline 1 & ثابتة & . & 1 & . & 1 & 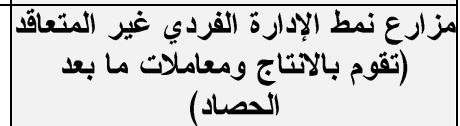 \\
\hline 1 & ثابتة & . & 1 & . & 1 & 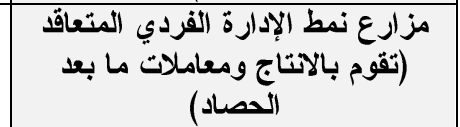 \\
\hline$\cdot, 00 Y \leqslant$ & تتاقصةً & . & 1 & $\cdot, \leqslant \leqslant V \checkmark$ & $\cdot, 00 Y \leqslant$ & مزارع نمط الإدارة من خلاملات ما بعد كاتلات \\
\hline 1 & ثابتة & . & 1 & . & 1 & 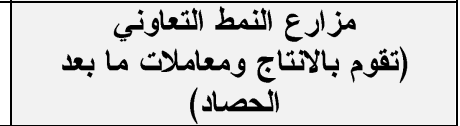 \\
\hline
\end{tabular}

كفاءة السعة (الحجم) = مؤشر الكفاءة لعو ائد الحجم الثابتة (CRS) / مؤشر الكفاءة لعوائد الحجم المتغيرة (VRS)

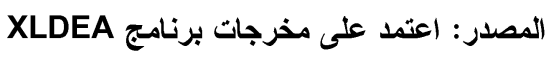

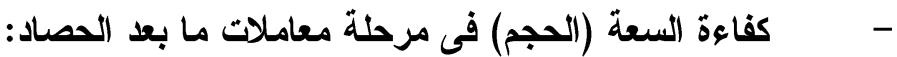

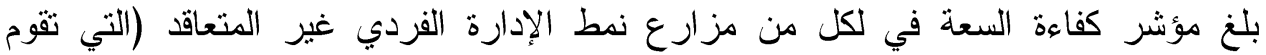

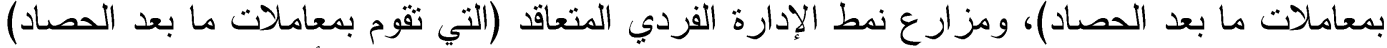

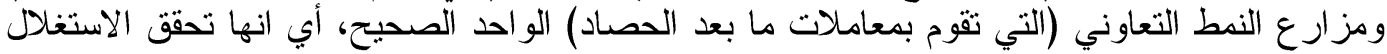

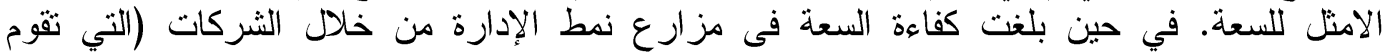

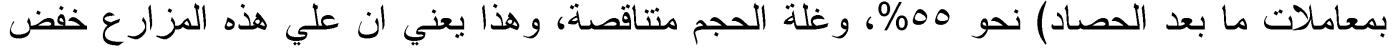

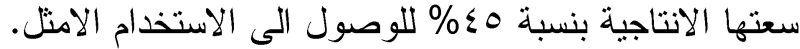

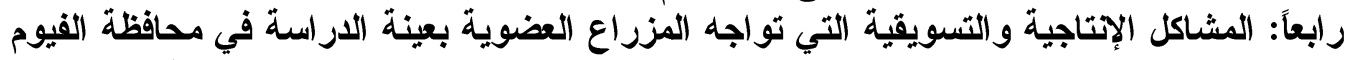

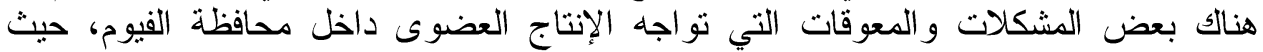

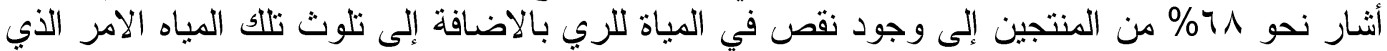

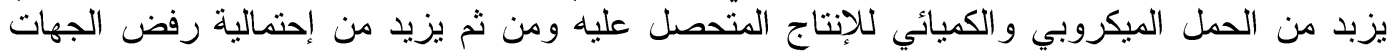

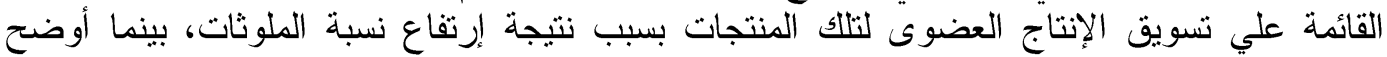

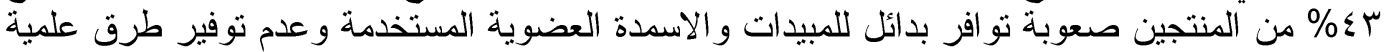

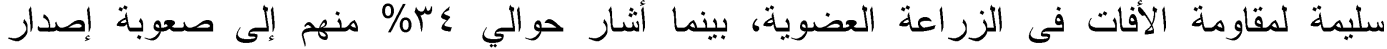

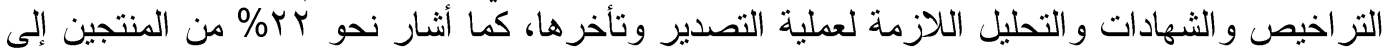

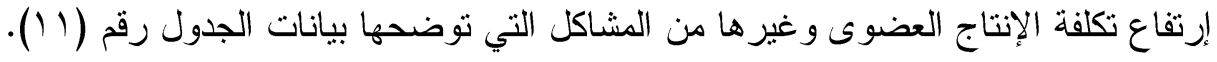

Fayoum J. Agric. Res. \& Dev., Vol. 33, No.2, July, 2019 
IVV

•

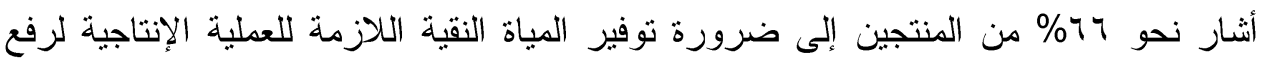

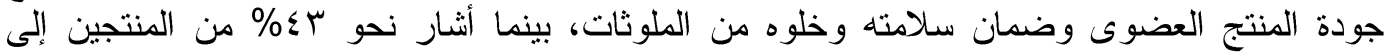

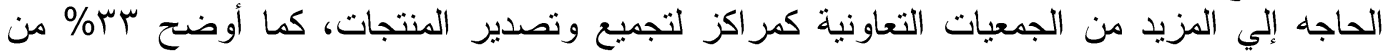

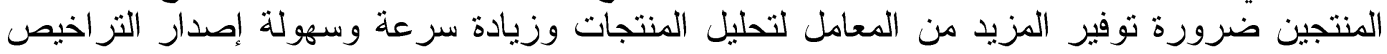

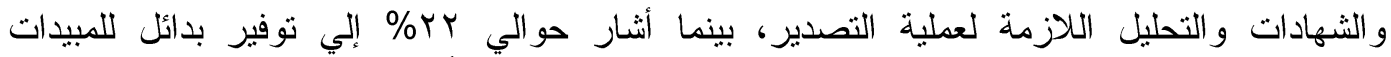

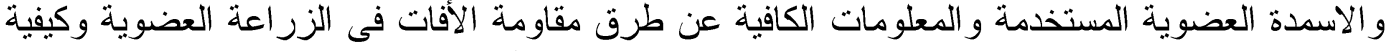

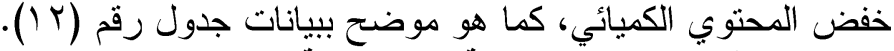
جلول (11): المشاكل الإنتاجية والتسويقية التي تواجه المزراع العضوية بعينة الاراسة في محافظة

\begin{tabular}{|c|c|c|}
\hline$\%$ & لت & الامشكلة \\
\hline & 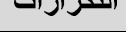 & المسلحة \\
\hline 79 & 71 & قلمّة وتلوث المياه \\
\hline$\leqslant \mu$ & $\leqslant \varepsilon$ & 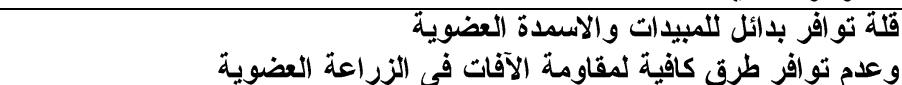 \\
\hline$r \varepsilon$ & To & صعوبة إصدار الثزراخيص و الثثهادات والتحليل اللازمة لعملية التصدير وتأخرها \\
\hline YY & r & إرتفاع تكلفة الإنتاج بالزر اعة العضوية \\
\hline 11 & 19 & عدم وجود فو اصل طبيعية بين الزراعة التقليدية و العضوية \\
\hline 17,0 & IV & انخفاض إنتاجية المحصول بالزراعة العضوية \\
\hline 17,0 & IV & غياب التوعية و الرعاية من جاتب الدولة \\
\hline$\Lambda, \vee$ & 9 & عدم ثُبات الأسعار بحيث تعادل الاسعار المرتفعة لعناصر التكاليف \\
\hline$\Lambda, Y$ & 9 & علم تو افر الالات الحديثة \\
\hline $\mathrm{V}, \mathrm{V}$ & $\wedge$ & غياب المعلومات عن اسعار واسواق الززراعة العضوية \\
\hline 0,1 & 7 & صغر الحيازة الزراعية \\
\hline
\end{tabular}

جدول (r I): الحلول المقترحة للتظلب علي مشكلات ومعوقات المزراع العضوية بعينة الاراسة في

\begin{tabular}{|c|c|c|}
\hline & & محانطة الفيوم \\
\hline$\%$ & التكر ار ات & المشكلة \\
\hline 77 & 71 & توفير المياة النقية اللازمة للعملية الإنتاجية \\
\hline$\varepsilon r$ & $\leqslant \varepsilon$ & الجمعيات التعاونية كمر اكز لتجميع وتصدير المنتجات \\
\hline rr & ro & توفير المزيد من المعامل لتحليل المنتجات \\
\hline rt & r & مقاومة الأففات لليدات و الاسمدة العضوية المستخدمة و المعلومات الكافية عن طرق \\
\hline
\end{tabular}

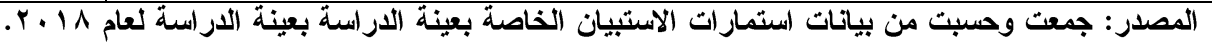

Fayoum J. Agric. Res. \& Dev., Vol. 33, No.2, July, 2019 
IVA

$$
\begin{aligned}
& \text { المر اجع: - (اجع } \\
& \text { 1- اعة حسن عبد المعطى محمد: "دور الارشاد الزراعى والجمعيات الاهلية فى نشر ممارسات }
\end{aligned}
$$

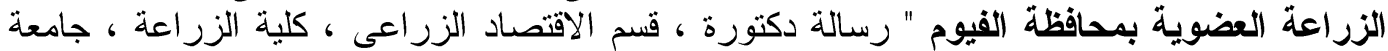

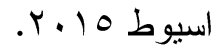

$$
\begin{aligned}
& \text { r- الطاشم علون السامر ائى: إدارة الاعمال المزرعية، دار اليازورى العلمية للنشر و التوزيع، عمان، }
\end{aligned}
$$

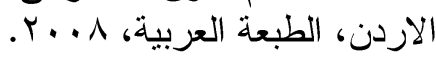

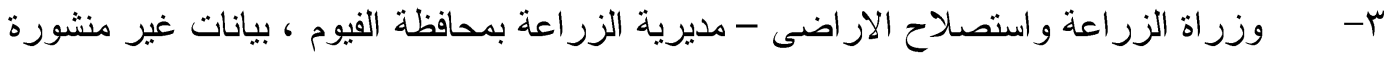

4- Boehlje, M.Dobbins: Checking Your Farm Business Management

Skills Purdue University, Agricultural Economics, 2001.

5- FIBL, IFOAM, The World of Organic Agriculture Statistics And emerging trends, IFOAM Organic International, 2017.

6- Mohamed Abd Alhmeda: Consumers' Motivations and Barriers towards organic food: the Case of Egypt, International Journal of Economics and Business Modeling, 2010, 3(3).

\title{
ANALYSIS OF ECONOMIC EFFICIENCY INDICATORS OF ORGANIC FARMS MANAGEMENT PATTERNS AT FAYOUM GOVERNORATE
}

\section{Prof. Dr. Abdel-Azeem Mohamed Mostafa, Prof. Dr. Enas El-Sayed Sadeq and Eng. Amr Al Sayed Ismail}

\begin{abstract}
The study aims at measuring the efficiency of the agricultural management patterns prevailing in organic agriculture in Fayoum governorate. The study found that the farms managed by administrative patterns in the form of cooperatives with higher efficiency than the other administrative patterns, both in production stages and post-harvest and marketing transactions, The productive efficiency of organic production, and that individual management patterns and patterns need to be developed in terms of the presence of specialized departments both for production or marketing to increase their productive, economic and administrative efficiency. As well as the possibility of strengthening the position of farms managed by companies and raising the efficiency of production and economic by reducing the capacity to reach the capacity of optimal production, and there are some problems and obstacles facing organic production in Fayoum Governorate, where farmers suffer from lack of water needed for irrigation in addition to Which increases the microbial and chemical load of the production obtained and thus
\end{abstract}

Fayoum J. Agric. Res. \& Dev., Vol. 33, No.2, July, 2019 
IV 9

increases the likelihood of rejection of the authorities based on the marketing of organic production of these products because of the high proportion of pollutants, and the difficulty of the availability of alternatives to pesticides and fertilizers And the lack of scientific methods for pest control in organic farming. Therefore, the study recommends the following:

1. Collecting farms in administrative patterns in the form of cooperatives to benefit from the efficiency of these administrative patterns, both in the production stages and post-harvest and marketing transactions, which lead to increased production and economic efficiency of organic production, development of individual management styles in terms of the existence of specialized departments for production or marketing to increase Productivity, economic and administrative efficiency.

2. Strengthening the position of the individual management farms in the ways of selling through contracting to improve their financial and marketing position, with awareness of the importance of keeping records and farm records and the existence of a simple accounting model that can be used to follow up the various production processes and compare the seasons to complete evaluations and follow-up and other administrative functions.

3. The importance of the farmer's attention to analyze the organic production obtained through the withdrawal of samples of the crop to ensure that it meets the requirements of organic production required.

4. Providing and supplying water suitable for agriculture to the places of agriculture that suffer from water shortage and pollution, as it represents the main obstacle to producers of organic agriculture in the province.

Fayoum J. Agric. Res. \& Dev., Vol. 33, No.2, July, 2019 